\title{
Макєঠovıкá
}

Tó 37 (2008)

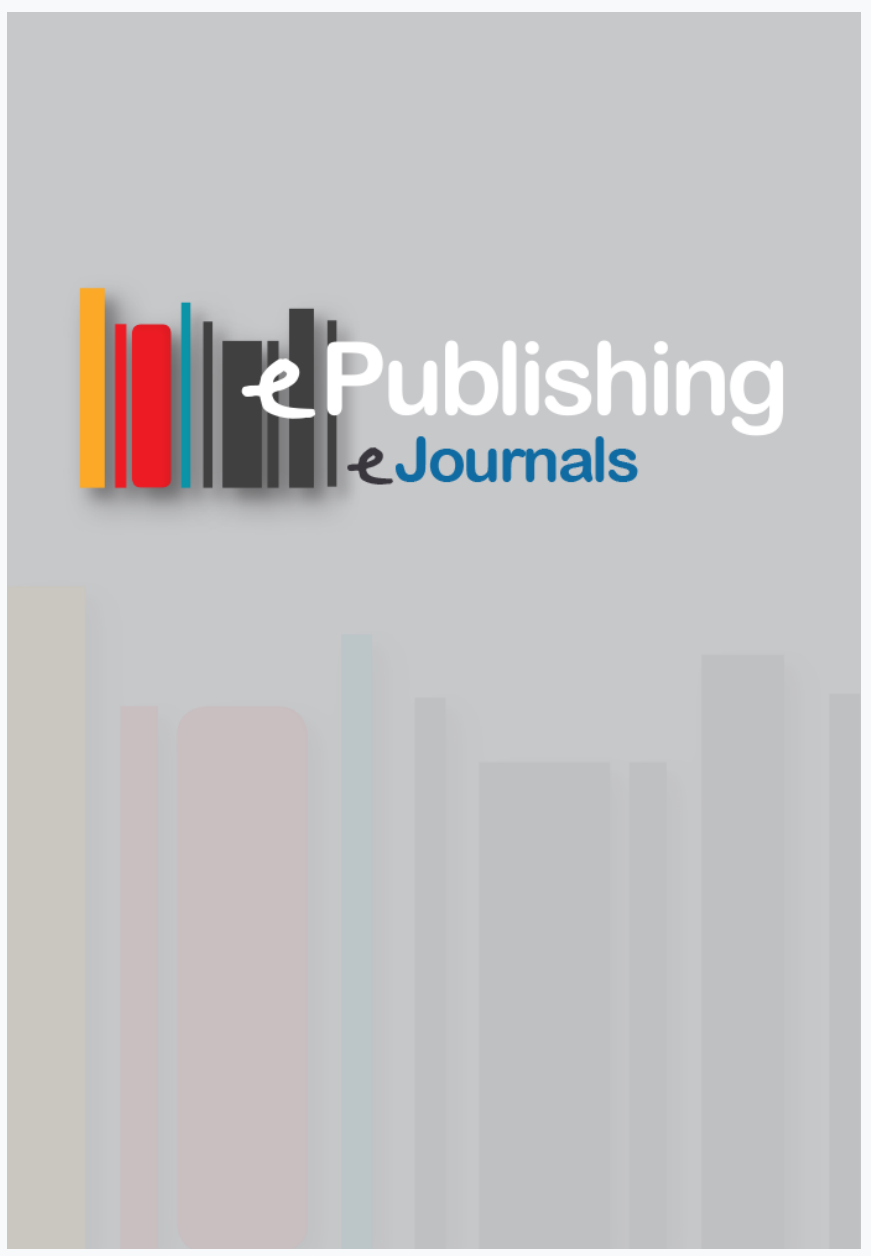

"Gepriesen seiest Du, die höher ist als alle, erreichend den Thron Gottes» - Überlegungen zu einem Koimesis-Zyklus in der Athanasioskirche in Voskopoje (Mosxhopolis)

\section{Karin Kirchhainer}

doi: $10.12681 /$ makedonika.47

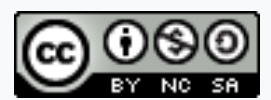

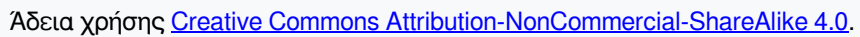

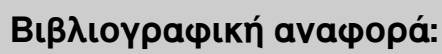

Kirchhainer, K. (2011). «Gepriesen seiest Du, die höher ist als alle, erreichend den Thron Gottes» - Überlegungen zu

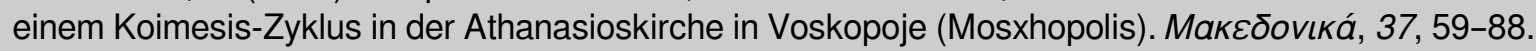

https://doi.org/10.12681/makedonika.47 


\section{«GEPRIESEN SEIEST DU, DIE HÖHER IST ALS ALLE, ERREICHEND DEN THRON GOTTES»- ÜBERLEGUNGEN ZU EINEM KOIMESIS-ZYKLUS IN DER ATHANASIOSKIRCHE IN VOSKOPOJE (MOSCHOPOLIS)}

Die Freskenausstattung der Athanasioskirche (Shën Thanasit) in Voskopoje (Moschopolis) in Südostalbanien zählt zu den umfangreichsten Bildensembles, die aus der nachbyzantinischen Zeit erhalten sind ${ }^{1}$. Erschaffen wurden die Malereien von den Künstlern Konstantin und Athanasios aus Korça ${ }^{2}$, welche die Ausmalung im Oktober 1744 fertig stellten, nachdem die Kuppelbasilika bereits 1724 errichtet worden war. Die Wand- und Gewölbeflächen der Kirche sind vollständig mit Fresken bedeckt. Erhalten haben sich zahlreiche Einzeldarstellungen von biblischen Personen und Heiligen sowie mehrere narrative Zyklen, die dem Leben Jesu, dem Opfertod verschiedener Märtyrer oder der Vita bedeutender Heiliger gewidmet sind.

1. Den Wandmalereien der Athanasioskirche wurde bislang noch keine eingehende Studie gewidmet, einige Bemerkungen zur Basilika und ihrer Malereien macht St. Adhami, «Tri bazilika të ndëtuara në Voskopojë brënda katër vjetëve», Monumentet 14 (1977) 159164. Zum Freskenprogramm der Kirche siehe K. Kirchhainer, «Die Bildausstattungen der Kirchen von Voskopoje und ihre Stellung in der nachbyzantinischen Wandmalerei des 18. Jahrhunderts», Patrimoine des Balkans. Voskopoje sans frontières 2004, Paris 2005, S. 53-73 und jüngst R. Rousseva, «Iconographic Characteristics of the Churches in Moschopolis and

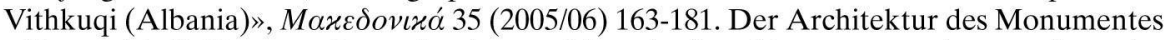

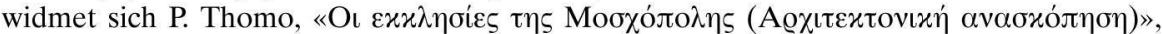

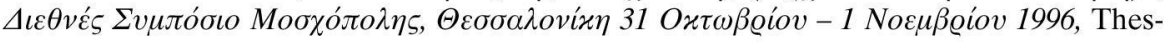
saloniki 1999, S. 49-55.

2. Beide Künstler sind bekannt und wiederholt in Stifterinschriften von Kirchen bezeugt. Es handelt sich um Brüder, die zwischen 1736 und 1783 tätig waren und mehrere Kirchen in Mittel- und Südalbanien sowie auf dem Berg Athos mit Fresken ausgestattet haben.

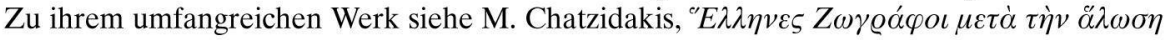
(1450-1830), Band 1, Athen 1987, S. 157f. (Athanasios); M. Chatzidakis - E. Drakopoulou,

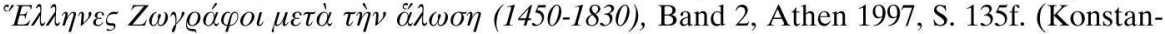
tin). Einen Überblick über die Tätigkeit der beiden Maler liefert T. Vinjau Caca, «Some Data about the Activity of Kostandin and Athanas Zografi from Korça and the Characteristics of their Art in the 18th Century», in: E. Drakopoulou (Hrsg.), Topics in Post-Byzantine Painting in Memory of Manolis Chatzidakis, Conference Proceedings 28-29 May 1999, Athen 2002, S. 203-216 (ohne Angaben zur verwendeten Literatur). Den Malereien des Konstan-

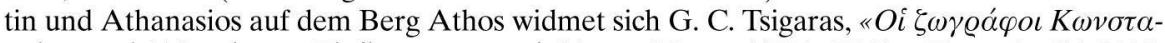

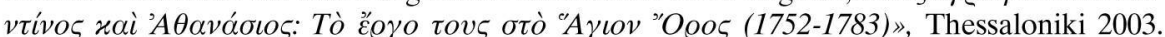
Zum Freskenensemble der Brüder im Ossuarium des Petrus- und Paulus-Klosters in Vithkuq siehe K. Kirchhainer, «Das Ossuarium des Petrus- und Paulus-Klosters in Vithkuq (Süd-

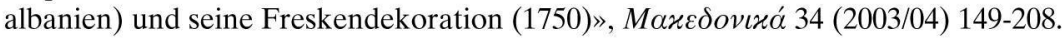


Im Mittelschiff wurde das gesamte Gewölbe des westlichen Joches einer Bildfolge eingeräumt, die verschiedene Begebenheiten um den Tod der Muttergottes schildert (Abb. 1-10). Das Ableben Mariens ist ausführlich dargelegt und mit einem Zyklus von insgesamt acht Szenen detailreich umschrieben. In seiner erzählerischen Breite geht die Darstellungsfolge deutlich über den Rahmen der meisten byzantinischen und nachbyzantinischen Bildsequenzen zum Marientod hinaus. Denn das Todesgeschehen der Gottesmutter wurde in den erhaltenen Denkmälern entweder in nur einigen wenigen Szenen entwickelt, oder erfuhr meistens nur durch die Komposition der Koimesis (dormitio) im Rahmen der Illustrationsfolge des Dodekaortons Wiedergabe. In dieser Darstellung, die meistens an der Westwand der Kirchen über dem Ausgang positioniert ist, wird das Entschlafen der Gottesmutter auf dem Sterbelager im Kreis ihrer Trauergemeinde gezeigt ${ }^{3}$. Mehrszenige KoimesisZyklen begegnen hin und wieder in Freskenausstattungen von Kirchen, die der Gottesmutter geweiht sind, und in denen analog zum Patrozinium mariologische Themen bei der bildnerischen Ausgestaltung vorherrschen ${ }^{4}$.

3. Die Ikonographie der Koimesis-Darstellung ist in der wissenschaftlichen Literatur ausführlich behandelt worden, aufgelistet werden im Folgenden nur grundlegende Publikationen zum Thema: Mit den frühmittelalterlichen Darstellungen beschäftigt sich O. Sinding, Mariae Tod und Himmelfahrt. Ein Beitrag zur Kenntnis der frühmittelalterlichen Denkmäler, Christiana 1903, S. 29-117. Der Ikonographie der Koimesis in der byzantinischen Malerei widmen sich ausführlich L. Wratislaw-Mitrović - N. Okunev, «La Dormition de la Sainte Vierge dans la peinture médievale orthodoxe», Byzantinoslavica 3,3 (1931) 134-173; E. M. Jones, «The Iconography of the Falling Asleep of the Mother of God in Byzantine Tradition», Eastern Churches Quarterly 9 (1951) 101-114; K. Kalokyres,

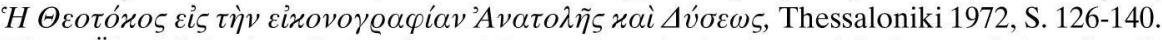
Einen Überblick über die Marientod-Darstellung in der byzantinischen und abendländischen Ikonographie liefern J. Mysliveć, «Tod Mariens», Lexikon der christlichen Ikonographie, Band 4 (1972), Sp. 333-338; G. Schiller, Ikonographie der christlichen Kunst, Band 4,2 Maria, Gütersloh 1980, S. 92-114 (im Folgenden: Iconographie, Bd. 4,2). Eingehend zur Entwicklung der Ikonographie des Koimesis-Bildes in der Ostkirche siehe Ch. Schaffer, Aufgenommen ist Maria in den Himmel. Vom Heimgang der Gottesmutter in Legende, Theologie und liturgischer Kunst der Frühzeit, Regensburg 1985, S. 39-55; K. Kreidl-Papadopoulos, «Koimesis», Reallexikon zur byzantinischen Kunst, Band 4 (1990), Sp. 136-182 mit zahlreichen Verweisen auf die ältere Literatur.

4. Beispiele bieten einige spätbyzantinischen Freskenausstattungen von Marien-Patrozinien in Serbien, siehe H. Hallensleben, Die Malerschule des Königs Milutin. Untersuchungen zum Werk einer byzantinischen Malerwerkstatt zu Beginn des 14. Jahrhunderts, Giessen 1963, S. 70-75; R. Hamann-Mac Lean, Grundlegung zu einer Geschichte der mittelalterlichen Monumentalmalerei in Serbien und Makedonien, Giessen 1976, S. $32-34$ und S. Radojčić, «Die Reden des Johannes Damaskenos und die Koimesis-Fresken in den Kirchen des Königs Milutin», Jahrbuch der Österreichischen Byzantinistik 22 (1973) 301-312. Wesentlich häufiger als Bildfolgen zum Marientod begegnen seit dem 14. Jahrhundert allerdings Zyklen des Akathistos-Hymnos, der in der nachbyzantinischen Malerei besondere Popularität genoß, zu diesem Thema siehe grundlegend G. Gounaris, «Die Ikonographie des Akathistos-Hymnos in der nachbyzantinischen Ikonenmalerei», in: G. Koch 
Dem achtszenigen Zyklus in der Athanasioskirche gebührt also besondere Beachtung, zumal das Patronat keine Betonung des Marienlebens im Bildprogramm erfordert. Überdies sind ausführliche Bildsequenzen zum Tod der Gottesmutter in der nachbyzantinischen Wandmalerei nicht besonders verbreitet, und sie enthalten in der Regel nicht mehr als drei Szenen ${ }^{5}$. Diese knapp formulierten Zyklen stehen im Einklang mit den Anweisungen des Malerhandbuches vom Berge Athos (Hermeneia), das nur drei Todesszenen für die bildnerische Ausschmückung von Kirchen vorsieht, bei denen es sich um das Entschlafen, die Grablegung und die leibliche Auffahrt der Gottesmutter in den Himmel handelt ${ }^{6}$. Auch in der Ikonenmalerei sind keine umfangreiche Zyklen zum Sterbegeschehen der Gottesmutter entwickelt worden. In den wenigen Fällen, in denen die Koimesis eine ikonographische Bereicherung erfuhr, geschah dieses lediglich durch die Hinzufügung von zwei Nebenszenen in die Komposition ${ }^{7}$.

Grundlage für die Ikonographie der Koimesis-Zyklen sind apokryphe Textquellen; die Evangelien berichten nichts von den Umständen des Marientodes. Zum Ableben der Gottesmutter sind dagegen zahlreiche außerbiblische Berichte überliefert, wobei sich mehrere Legendenvarianten herausgebildet haben ${ }^{8}$. Bedeutung in der byzantinischen Kirche erlangte ein apo-

(Hrsg.), Byzantinischen Malerei. Bildprogramme - Ikonographie - Stil, Symposion in Marburg vom 25.-29.1997, Wiesbaden 2000, S. 79-90 und jüngst I. Spatharakis, The Pictoral Cycles of the Akathistos Hymn for the Virgin, Leiden 2005, S. 98-106 mit zahlreichen Verweisen auf die ältere Literatur.

5. $\mathrm{Zu}$ den in den Kirchen abgebildeten Szenen siehe weiter unten bei den Ausführungen zur Ikonographie.

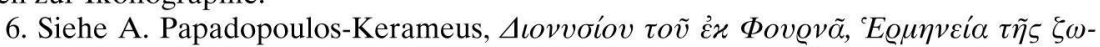

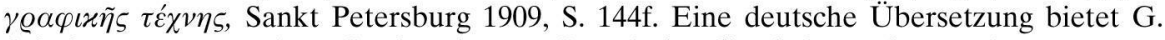
Schäfer, EPMHNEIA THC ZЛГРAФIKHC. Malerhandbuch des Malermönches Dionysios vom Berge Athos, München ${ }^{2} 1983$, S. 127.

7. Beispiele bieten verschiedene Papierikonen des 18. Jahrhunderts, siehe D. Papa-

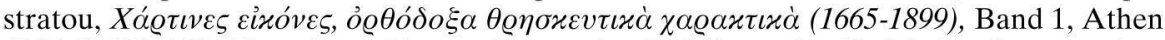
1986, S. 153-163. Als weiteres Exempel kann eine Holzikone des 18. Jahrhunderts aus dem Marien-Kloster in Goranxi (Albanien) angeführt werden, siehe Ausstellungs-Katalog Trésors d'art Albanais, Icônes byzantines et post-byzantines du XIIe au XIXe siècle, Nizza 1993 , S. 108f, Kat. 80.

8. $\mathrm{Zu}$ den verschiedenen apokryphen Berichten siehe F. A. Lehner, Die Marienverehrung in den ersten Jahrhunderten, Stuttgart 1881, S. 242-255; Sinding, op.cit., S. 1-28; M. Jugie, La mort et l'Asomption de la Sainte Vierge, Vatikanstadt 1944; A. Wenger, L'Assomption de la Très Vierge dans la tradition byzantine du VIe au Xe siècle. Études et documents, Paris 1955; H. Daniel-Rops, Die apokryphen Evangelien des Neuen Testaments, Zürich 1956, S. 94-114; Kalokyres, op.cit., S. 263-265; Schiller, Iconographie, Bd. 4,2, op.cit., S. 8388; L. Heiser, Maria in der Christus-Verkündigung des orthodoxen Kirchenjahres, Trier 1981, S. 296-314; Schaffer, op.cit., S. 13-37; M. van Esbroeck, Aux orgines de la Dormition de la Vierge, Études historiques sur les traditions orientales, Aldershot 1995; S. C. Mimouni, Dormition et assomption de Marie. Histoire des traditions anciennes, Paris 1995; Ders., La 
krypher Text, der unter dem Pseudonym des Apostels Johannes verfasst wur$\mathrm{de}^{9}$. Größere Verbreitung gewann aber eine Homilie zum Marientod, die Erzbischof Johannes von Thessaloniki um 620 anlässlich der Einführung des Koimesis-Festtages in seiner Stadt vorgetragen haben soll ${ }^{10}$. Seine Ausführungen zum Todesgeschehen fanden kirchliche Anerkennung und werden am Festtag der Koimesis (15. August) in der Morgenliturgie (Orthros) verlesen ${ }^{11}$. Durch die Aufnahme des Textes in die Liturgie war er auch die wichtigste Inspirationsquelle für die Ikonographie des Marientodes ${ }^{12}$. Relevant für die byzantinischen Bildformulierungen ist außerdem eine gegen Ende des 5. Jahrhunderts im Osten entstandene apokryphe Schrift, die auf Bischof Meletios von Sardes ( $†$ um 180) zurückgehen soll ${ }^{13}$, sie prägte aber deutlicher die abendländischen Bildschöpfungen ${ }^{14}$. Für die ikonographische Bereicherung der Koimesis-Darstellung spielten darüber hinaus Hymnendichtungen und Predigten von verschiedenen Kirchenvätern und nachfolgenden kirchlichen $\mathrm{Au}$ toren eine nicht unerhebliche Rolle ${ }^{15}$.

Die Bildsequenz zum Marientod in der Athanasioskirche umfasst folgende Szenen: Die Ankündigung des Todes durch den Erzengel Gabriel (Abb. 2), das Gebet der Gottesmutter am Ölberg, die Verteilung der Kleider an die Witwen (Abb. 3), die Versammlung der Apostel am Bett Mariens (Abb. 4), das Entschlafen (Koimesis) der Gottesmutter auf dem Sterbebett (Abb. 5), die Überführung des Leichnams zum Grab (Abb. 6), die Apostel am leeren Grab in Verbindung mit der leiblichen Auffahrt Mariens in den Himmel (Abb. 7) und schließlich die Höllenfahrt der Gottesmutter (Abb. 8).

Bei der Verteilung der Szenen auf die Wand- und Gewölbeflächen spielte die zeitliche Abfolge der Ereignisse am Lebensende der Gottesmutter eine untergeordnete Bedeutung. Vielmehr bildeten die zur Verfügung stehenden Wandflächen dieses Raumbereichs die prägenden Faktoren für die Po-

tradition greque de la dormition et de l'assomption Marie, Paris 2003, beide Publikationen enthalten zahlreiche Verweise auf die ältere Literatur.

9. Johannis Liber de dormitione Mariae, C. Tischendorf, Apocalypses apocryphae, Leipzig 1866, S. 95-112. Eine deutsche Übersetzung gibt Lehner, op.cit., S. 244-253.

10. Die Homilie wurde ediert von M. Jugie, Patrologia Orientalis 19 (1926) S. 344-438. Deutsche Übersetzungen geben Heiser, op.cit., S. 299-301 und Schaffer, op.cit., S. 34-37.

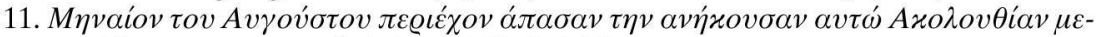

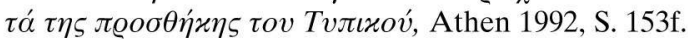

12. Kreidl-Papadopoulos, op.cit., Sp. 141.

13. Pseudo-Meletio, Liber de transitu Virginis Mariae, in: J. P. Migne (Hrsg.), Patrolologiae cursus completus, series greaca, 5, col 1231-1240. In deutscher Übersetzung bei Daniel-Rops, op.cit., S. 95-104 und in Auszügen bei Schaffer, op.cit., S. 14-17.

14. Schiller, Iconographie, Bd. 4,2, op.cit., S. 121-131.

15. Siehe dazu ausführlich Schaffer, op.cit., S. 13-37; Heiser, op.cit., S. 302-314. Speziell der Einflussnahme der Reden des Johannes Damaskenos auf die Koimesis-Fresken in den Kirchen des Königs Milutin in Serbien widmet sich Radojčić, op.cit., S. 301-312. 
sitionierung der Darstellungen. Priorität bei der Verteilung wurde der Szene der Koimesis eingeräumt, die ihren nahezu kanonischen Platz an der Westwand behauptet ${ }^{16}$. Sie bedeckt die oberen Flächen dieser Wand, und unterhalb von ihr schließen sich links die Szene der Todesankündigung durch Gabriel und rechts die Versammlung der Apostel am Bett der Gottesmutter an, bei dem Maria den Jüngern ihr nahes Ende mitteilt. Vier Szenen des Zyklus bedecken den südlichen Teil des Tonnengewölbes. Im unteren Register werden das Gebet Mariens am Ölberg und die Verteilung ihrer Kleider an die Witwen gezeigt. Darüber schließt sich in der nächsten Zone die Prozessionsszene mit der Grabtragung des Leichnams (translatio) verknüpft mit der Jephonias-Geschichte an. Im obersten Register, unterhalb des Gewölbescheitels, folgt schließlich die Darstellung der Apostel am leeren Grab, in der die leibliche Auffahrt der Gottesmutter in den Himmel (assumptio corporis) einbezogen ist, bei der Maria dem Apostel Thomas ihren Gürtel übergibt. Die letzte Szene des Zyklus ist schließlich im nördlichen Teil des Gewölbes lokalisiert. Dort befindet sich im unteren Register die Darstellung der Höllenfahrt Mariens. Darüber ist einer Darstellung ein hohes Bildfeld eingeräumt worden, das kein integraler Bestandteil des Marien-Zyklus ist. Abgebildet wurde der Kindermord zu Bethlehem (Abb. 9), der ausgedehnt geschildert die gesamte Fläche bis zum Gewölbescheitel einnimmt. Auch auf der Westwand findet sich zwischen der Todesankündigung an Maria und der Versammlung der Apostel am Bett der Gottesmutter eine Darstellung, die dem Koimesis-Zyklus im eigentlichen Sinne nicht zuzurechnen ist. Wiedergabe erfuhr ein Christusbild, das als Anapeson bezeichnet wird (Abb. 10).

In der byzantinischen Monumentalmalerei lässt sich seit dem Ende des 13. Jahrhunderts die Tendenz beobachten, dass den Ereignissen um den Tod der Gottesmutter eine zunehmende Bedeutung beigemessen wird. Dieses äussert sich darin, dass die Komposition der Koimesis durch Komplementärszenen erweitert wird, die sowohl die Einleitung des Todesgeschehens abbilden als auch Begebenheiten nach dem Ableben schildern. In den älteren Darstellungen des Marientodes beschränkten sich die Maler in der Regel noch auf die Wiedergabe des Entschlafens der Gottesmutter im Kreis ihrer Trauergemeinde. Abgebildet ist Maria auf einem Sterbebett, zu dem sich die trauernden Apostel hinabbeugen. Hinter dem Lager steht in der Mitte der von fliegenden Engeln begleitete Jesus, der die als Wickelkind gekennzeich-

16. Zur Funktion der Koimesis-Darstellung an diesem Ort des Kirchenraumes siehe K. Kirchhainer, Die Bildausstattung der Nikolauskirche in Thessaloniki. Untersuchungen zu Struktur und Programm der Malereien, Weimar 2001, S. 93-95 mit Verweisen auf die ältere Literatur. 
nete Seele seiner Mutter in Empfang nimmt. Hinzu können Bischöfe und auch trauernde Frauen treten, deren Anzahl variabel ist ${ }^{17}$.

Die Ikonographie dieser kanonischen Kernszene erfährt in der palaiologischen Epoche bisweilen Erweiterung, in der ein komplexer Koimesis-Typus entsteht, der das Entschlafen und die körperliche Auffahrt der Gottesmutter in den Himmel in einer Komposition vereinigt zeigt ${ }^{18}$. Im Zentrum des oberen Bildfeldes ist über dem Sterbelager die empor fahrende Maria in einer Gloriole hinzugefügt, die von Engeln gen Himmel geleitet wird. Die Gottesmutter wendet sich gelegentlich dem heranfliegenden Apostel Thomas entgegen, dem sie als Zeugnis ihrer leiblichen Auffahrt ihren Gürtel übergibt ${ }^{19}$.

Diesem komplexen Koimesis-Typus werden ab dem Ende des 13. Jahrhunderts schließlich noch zusätzliche Nebenszenen beigeordnet, die das Thema ausführlicher schildern. Belegt sind diese Begleitepisoden zuerst in der serbischen Wandmalerei und zwar in der Koimesis-Darstellung in der Peribleptoskirche (Sv. Kliment) in Ohrid $(1295)^{20}$. Es existieren aber Bildzeugnisse, die darauf hinweisen, dass schon zuvor narrative Sequenzen zum Marientod vorkamen. So sind beispielsweise in den Wandmalereien der Kirche S. Maria Egiziaca (872-882) im Tempel der Fortuna Virilis in Rom die Episoden der Verkündigung des Todes an Maria durch Christus, der Empfang der Apostel durch Johannes vor dem Haus der Gottesmutter sowie der Transport von Aposteln durch Engel zum Hause Mariens bewahrt ${ }^{21}$. Auch das von der

17. Szenen des Marientodes sind erst aus der nachikonoklastischen byzantinischen Malerei bewahrt. Erhaltene Schriftquellen liefern aber Auskünfte, dass das Thema schon vor dem Bilderstreit existiert haben muss, siehe Kreidl-Papadopoulos, op.cit., Sp. 145. Einen materiellen Beleg dafür liefern Fragmente von Wandmalereien, die kürzlich im Benediktiner-Kloster St. Martin in Disentis in Graubünden (Schweiz) zutage gefördert worden sind. Erhalten haben sich Teile einer Darstellung des Marientodes, die wahrscheinlich von so genannten Ikonoklasmus-Flüchtlingen um 750 geschaffen worden sind. Diese byzantinischen Künstler zählten das Bildthema also bereits im 8. Jahrhundert zu ihrem Darstellungsrepertoire und trugen zweifellos mit dazu bei, dass die Ikonographie der Koimesis-Szene aus Byzanz nach Westeuropa gelangte. Zu diesen Freskenresten siehe W. Studer, Disentis/Mustér, «St. Martin: Die älteste materiell fassbare Koimesis-Darstellung der Welt», Jahresberichte des Archäologischen Dienstes Graubünden und der Denkmalpflege Graubünden 2004 (2005) 64-79. Einen Überblick über sämtliche aufgefundenen Reste frühbyzantinischer Fresken in St. Martin gibt der Ausstellungs-Katalog Byzanz in Disentis, Fragmente frühbyzantinischer Monumentalmalerei, Rätisches Museum Chur 18. 11. 2005 bis 12. 03. 2006, Chur (2005).

18. Schiller, Iconographie, Bd. 4,2, op.cit., S. 95; Kreidl-Papadopoulos, op.cit., Sp. 146.

19. Die Wolkenfahrt der Apostel zum Begräbnis Mariens begegnet bereits in der Mitte des 11. Jahrhunderts in den Wandmalereien der Sophienkirche in Ohrid. Ab dem 13. Jahrhundert wird dann auch dem zum Ereignis zu spät kommenden Thomas von Maria der Gürtel übergeben, siehe Schiller, op.cit., S. $118 f$.

20. Siehe weiter unten Anm. 23.

21. Zu den Wandmalereien siehe J. Lafontaine, Peintures médiévales dans le Temple dit de la Fortune Virile à Rome, Brüssel-Rom 1959, S. 31-35 mit Abb. 7-9. 
byzantinischen Ikonographie beeinflusste Bildprogramm der Bronzetür der Kathedrale im russischen Susdal (1227-1237) widmet sich mit mehreren Szenen den Ereignissen um den Tod der Gottesgebärerin. Abgebildet sind das Entschlafen Mariens, die Niederlegung ihrer Kleider, ihre Grabtragung in Verbindung mit der Jephonias-Geschichte, ihre leibliche Auffahrt mit der Gürtelspende an Thomas und schließlich ihre Interzession vor Christus ${ }^{22}$. Die beiden Beispiele in Rom und Susdal belegen zwar nur außerhalb des Byzantinischen Reiches die Existenz von Koimesis-Zyklen, doch räumt insbesondere die auf byzantinische Ursprünge zurückgehende Bildsequenz in Susdal die Möglichkeit ein, daß es in Konstantinopel vor der Eroberung durch die lateinischen Kreuzfahrer (1204) ebenfalls Darstellungsfolgen zum Heimgang der Gottesmutter gab ${ }^{23}$.

Die ältesten belegten Komplementär-Szenen zum Tod der Gottesmutter wurden in die Darstellung der Koimesis selbst aufgenommen und der Sterbeszene bereichernd hinzugefügt. Entsprechend sind in der Darstellung des Marientodes in der Peribleptoskirche in Ohrid (1295) mehrere Begleitepisoden integriert, wodurch verschiedene Szenen in einem breiten Bildfeld zu einer komplexen Komposition verschmelzen. Eingebunden wurden vier Nebenszenen, von denen sich zwei ante und zwei post mortem ereignet haben ${ }^{24}$.

Später, ab der Mitte des 14. Jahrhunderts, gingen die Maler in Serbien teilweise dazu über, den Begleitszenen eigene Bildfelder einzuräumen. Als Beispiel können die Fresken in der Pantokratorkirche im Kloster von Dečani (1335-50) angeführt werden, in denen eine knapp formulierte Koimesis-Darstellung von vier eigens gerahmten Bildfeldern flankiert wird, in denen Episoden vor und nach dem Ableben Mariens gezeigt werden ${ }^{25}$.

Bei der Gestaltung des nachbyzantinischen Koimesis-Zyklus in der Athanasioskirche wurde eine Präsentation der Darstellungsfolge in einzeln

22. Kreidl-Papadopoulos, op.cit., Sp. 158 mit Hinweisen auf die ältere Literatur. Gute Abbildungen der Szenen bietet A. N. Ovchinnikov, Golden Gates in Suzdal, Moskau 1978, Abb. 40-54.

23. Radojčić, op.cit., 307. Dieselbe Auffassung vertreten bereits Schiller, Iconographie, Bd. 4,2, op.cit., S. 118 und Kreidl-Papadopoulos, op.cit., Sp. 162.

24. Siehe R. Hamann-Mac Lean - H. Hallensleben, Die Monumentalmalerei in Serbien und Makedonien vom 11. bis zum frühen 14. Jahrhundert, Giessen 1963, Plan 21 und 22; Hallensleben, op.cit., S. 70-75; Hamann-Mac Lean, op.cit., S. 32-34.

25. Siehe J. Lafontaine-Dosogne, «Les cycles de la Vierge dans l'église de Dečani: Enfance, Dormition et Akathiste», Dečani et l'art Byzantin au Milieu du XIVe siècle. A l'occasion de la celebration de 650 ans du monastère de Dečani, Septembre 1985, Belgrad 1989, S. 311-313 mit Abb. 3 und 4 mit Verweisen auf die ältere Literatur. Ein weiteres Beispiel bietet der vierszenige Koimesis-Zyklus in der Südkapelle der Aphentikokirche (Brontocheion) in Mistra (Mitte 14. Jh.), siehe S. Dufrenne, «Quelques aspects de l'iconographie des peintures de Mistra au temps du Despotat de Morée», L'école de la Morava et son temps, Symposium de Resava 1968, Belgrad 1972, S. 26-28. 
gerahmte Szenen, wie sie bereits in den spätbyzantinischen Fresken von Dečani vorliegt, vorgenommen. Auch an der Ausformulierung der Darstellungen von Konstantin und Athanasios lässt sich meistens eine Anlehnung an ältere Vorlagen beobachten. Demgemäß folgt die Wiedergabe der Szene der Todesankündigung durch den Erzengel Gabriel (Abb. 2) Bildschöpfungen, die schon in der spätbyzantinischen Wandmalerei belegt sind ${ }^{26}$. Dargestellt ist, wie der heranfliegende Erzengel der ihm zugewandten Gottesmutter den Palmzweig des Paradieses überbringt ${ }^{27}$. In der Ikonographie der Szene ist die Darreichung des Palmzweiges das konstante und verbindliche Element, die Position und Körperhaltung der beiden Verkündigungs-Figuren variiert dagegen in den überlieferten Bildbeispielen; außerdem kann das Geschehen im Haus oder am Ölberg gezeigt werden ${ }^{28}$. In der Athanasioskirche ist die Innenraum-Darstellung durch den Thron und das Lesepult der Gottesmutter besonders detailfreudig gestaltet ${ }^{29}$.

Die Szene des Gebets der Gottesmutter am Ölberg (Abb. 3) wurde wie die der Ankündigung des Todes in viele Koimesis-Zyklen der spätbyzantinischen Wandmalerei aufgenommen. Beide Begebenheiten sind die am häufigsten abgebildeten der ante mortem Ereignisse. Dabei war die Ikonographie der Szene des Gebets am Ölberg nur wenigen Veränderungen unterworfen ${ }^{30}$.

26. Zur Wiedergabe des Themas in der byzantinischen Wandmalerei siehe WratislawMitrović - Okunev, op.cit., S. 158-165.

27. Der Palmzweig wird in verschiedenen Legendenvarianten als Zeichen des Paradieses erwähnt, in das Maria mit ihrem Tod eingeht, siehe Schaffer, op.cit., S. 13-23.

28. In der Peribleptoskirche in Ohrid (1295) fliegt der Engel von rechts in einer Landschaftskulisse auf die links stehende Maria zu, siehe G. Millet - A. Frolow, La peinture $d u$ moyen âge en Yougoslavie, Band 3, Paris 1962, Taf. 11,2. Dagegen sind in der Nikolauskirche in Curtea de Argeș in der rumänischen Walachei (Ende 14. Jh.) beide Figuren stehend zu Seiten eines Pfeilers abgebildet, wobei Gabriel von links an Maria heranschreitet, siehe O. Tafrali, Monuments byzantins de Curtéa de Argeş, Paris 1931, Taf. LXIII,1. In den nachbyzantinischen Fresken der Demetrioskirche in Palatitsia Emathias (1570) fliegt der Engel von links auf die auf einer Mauer stehenden Gottesmutter zu, siehe A. G. Tourta, Oı vaoi

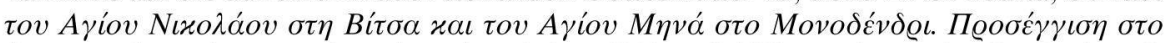

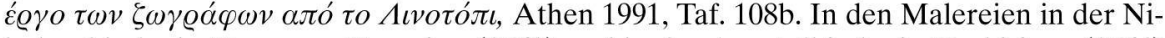
kolauskirche in Kapesovo Zagoriou (1761) und in der Apostelkirche in Derbisiana (1764) fliegt der Engel von links an die in einer Landschaft knienden Muttergottes heran, siehe D.

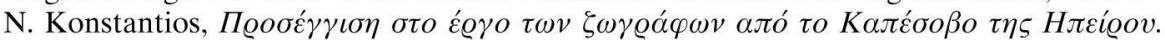

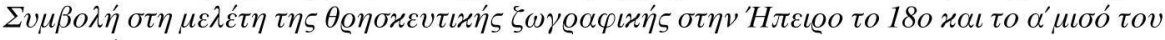
19 ov aı́vva, Athen 2001, Abb. 1 und 16b.

29. Nach Wratislaw-Mitrović - Okunev, op.cit., S. 160 beruht die Ikonographie der Todesankündigung im Innenraum auf dem Bericht des Bischofs Meletio von Sardes. Nach dieser Legenden-Variante fand die Überbringung des Palmzweiges im Hause der Eltern des Johannes in Jerusalem statt, in dem Maria gewohnt haben soll, vgl. Schaffer, op.cit., S. 14.

30. Zu den erhaltenen mittelalterlichen Darstellungen und ihrer Ikonographie siehe Wratislaw-Mitrović - Okunev, op.cit., 158-160 und Schiller, Iconographie, Bd. 4,2, op.cit., S. $124 \mathrm{f}$. 
Maria ist stets mit zum Gebet ausgebreiteten Armen in einer Landschaft anzutreffen, wobei ihre Körperhaltung aufrecht oder kniend sein kann. Vor der Muttergottes erwachsen aus einem Felsen mehrere Bäume, die sich vor ihr verneigen. Die Szene ist zum ersten Mal in der Peribleptoskirche in Ohrid bezeugt, wo sie zusammen mit der Todesankündigung in eine Landschaftskulisse eingebettet is $\mathrm{t}^{31}$; in der nachbyzantinischen Malerei wurde sie eher selten dargestellt. Bemerkenswert ist, dass in die Darstellung in der Athanasioskirche ein Himmelsegment hinzugefügt ist, aus dem die Hand Gottes heraus Maria segnet ${ }^{32}$.

Die Verteilung der Kleider an die trauernden Witwen (Abb. 3) begegnet nicht sehr oft in den Koimesis-Bildfolgen ${ }^{33}$. Maria ist links vor einem Gebäude dargestellt und hält ein Gewand in ihren Händen. Sie wendet sich nach rechts den zwei Witwen zu, von denen die vordere das Kleidungsstück entgegennimmt. Hinter dieser folgt die andere Witwe, an deren rechter Schulter ein Stück eines weiteren Gewandes erkannt werden kann. Die Szene der Verteilung der Kleider an die trauernden Frauen begegnet in der Kirche der Mariengeburt in Matejić (1356/57), in der Nikolauskirche Curtea de Argeş (Ende 14. Jh.) und in der Demetrioskirche in Palatitsia Emathias (1570). Diesen Darstellungen ist gemeinsam, dass die Gottesmutter nicht vor, sondern in einem Haus gezeigt wird. Darüber hinaus ist sie sitzend wiedergegeben, und die Witwen treten an sie heran ${ }^{34}$. Für die stehende Wiedergabe Mariens vor einem Gebäude lassen sich keine unmittelbaren Vergleichsbeispiele anführen.

Die Szene der Versammlung der Apostel am Bett der Gottesmutter, bei der Maria den Jüngern in einem Gespräch ihr nahes Ende ankündigt (Abb. 4), zählt zu den selten abgebildeten Ereignissen um den Tod der Gottesmut$t^{35}{ }^{35}$. Im Zentrum der schlecht erhaltenen Darstellung sitzt Maria auf einem vertikal angeordneten Bett. Sie wendet ihren Oberkörper nach rechts, die Haltung ihrer Hände ist nicht mehr erkennbar. Von links und rechts beugen sich ihr zwei Gruppen von Aposteln entgegen, die brennende Kerzen in ihren

31. Siehe Millet - Frolow, op.cit., Taf. 11,1.

32. Dasselbe Begleitmotiv ist in der Ölbergszene in der Nikolauskirche in Curtea de Argeş anzutreffen, siehe Tafrali, op.cit., Taf. LXII, 1.

33. Zur Darstellung des Themas in der byzantinischen Monumentalmalerei siehe Wratislaw-Mitrović - Okunev, op.cit., 158-161.

34. In Matejić ist die Szene der Verteilung der Kleider mit der Episode der Todesankündigung zu einer Komposition verschmolzen worden, denn es fliegt zusätzlich der Engel der Verkündigung von links oben auf Maria zu, siehe Wratislaw-Mitrović - Okunev, op.cit., Taf. XIII, 2. In Curtea de Argeş sitzt Maria auf einem Bett, an das nur eine Witwe herantritt, sie Tafrali, op.cit., Taf. LXII,1. Die Darstellung in Palatitsia Emathias zeigt ebenfalls Maria auf einem Thron, dem sich drei Witwen nähern, siehe Tourta, op.cit., Taf. 108a.

35. Zur Ikonographie der Szene siehe Schiller, Iconographie, Bd. 4,2, op.cit., S. 124126, die einige abendländische Bildbeispiele anführt. 
Händen halten. Für die Ikonographie der Szene lassen sich in den bewahrten Darstellungen kaum Parallelen ausmachen. Eine verwandte Darstellung befindet sich im Katholikon des Nikolaus-Klosters in Galataki auf Euböa (1586), in der ebenfalls die Apostel von beiden Seiten an die auf dem Bett sitzende Maria herantreten ${ }^{36}$.

Beim Aufbau der Komposition der Koimesis (Abb. 5) orientierten sich die Maler an der klassischen Ausformulierung der Szene, die in der palaiologischen Epoche abgeschlossen war $^{37}$. Entsprechend liegt die Gottesmutter von links nach rechts gerichtet auf einem bildparallel angeordneten Bett, um das sich die Trauernden versammelt haben. Die Trauergemeine besteht aus elf Aposteln (der zum Begräbnis zu spät gekommene Thomas fehlt), drei Bischöfen ${ }^{38}$ und mehreren Frauen. Hinter dem Totenlager steht der von einer Mandorla hinterfangene Christus, der von zehn Engeln begleitet wird und die Seele seiner Mutter bereits in Empfang genommen hat. Beiderseitig schliessen sich zwei Gebäude an, in deren Fensteröffnungen die Büsten der Hymnenschreiber Johannes von Damaskus (links) und Kosmas von Maiouma (rechts) zu sehen sind. Die beiden Poeten zählen zum festen Bestandteil der

36. Siehe T. Kanari, Les peintures du Catholicon du Monastère de Galataki en Eubée, 1586. Le Narthex et la Chapelle de Saint-Jean-le-Précurseur, Athen 2003, S. 199 mit Abb. 104 (Auf der Aufnahme ist nur der linke Teil der schlecht bewahrten Szene erkennbar). Eine ähnliche Ikonographie bietet das Fresko mit der Darstellung der Ankunft der Apostel in der Koimesiskirche in Gračanica (1321). Allerdings nähern sich hier alle Jünger von rechts dem Bett der Gottesmutter; außerdem sind in die Szene die beiden Witwen miteinbezogen, die am Kopfende zu Seiten Mariä stehen, siehe Wratislaw-Mitrović - Okunev, op.cit., Taf. IX,1 oder V. L. Petković, La peinture Serbe du moyen âge, Band 1, Belgrad 1930, Taf. 46b. Eine vergleichbare Bildformulierung, bei der Maria auf einem Bett sitzend von verschiedenen Personengruppen umgeben wird, liegt in der Südkapelle der Aphentiko-Kirche (Brontocheion) in Mistra (Mitte 14. Jh.) vor. Dabei handelt es sich um eine Szene, in der sich Maria von den ihr Nahestehenden verabschiedet, siehe Wratislaw-Mitrovic - Okunev, op. cit., Zeichnung 11 oder Dufrenne, op.cit., Zeichnung 2. Thronend wird Maria in der Szene im Narthex des Diliou-Klosters in Ioannina (1542/43) gezeigt, wobei die Apostel von rechts an sie herantreten. In der Kirche ist außerdem wiedergeben, wie sich Maria von den ihr nahestehenden Frauen verabschiedet. Bemerkenswert ist, dass diese post mortem Szenen neben der Koimesis in einen Kindheitszyklus der Gottesmutter eingebunden wurden,

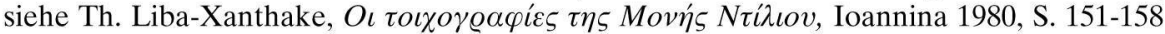
mit Abb. 63-65 oder M. Garidis - A. Paliouras (Hrsg.), Monasteries of the Island of Ioannina, Painting, Ioannina 1993, S. 223f. mit Farbabb. 431-432.

37. Zu diesem Typus und seiner Genese siehe grundlegend Schiller, Iconographie, Bd. 4,2, op.cit., S. $92-95$ und Kreidl-Papadopoulos, op.cit., Sp. 145-160 mit zahlreichen Hinweisen auf die ältere Literatur.

38. Es handelt sich um die drei heiligen Bischöfe Dionysios Areopagites, Hierotheos und Timotheos, die auch im Malerhandbuch für die Darstellung der Koimesis vorgesehen sind, siehe Papadopoulos-Kerameus, op.cit., S. 144 und Schäfer, op.cit., S. 127. Die Einbindung von Bischöfen in die Szene soll auf der Interpretation einer Textstelle bei Dionysios Pseudo-Areopagites beruhen, nach der vier Bischöfe bei der Dormitio anwesend waren, siehe dazu Wratislaw-Mitrović - Okunev, op.cit., $138 f$. 
Szene und die von ihnen verfassten und auf ihren Schriftrollen eingetragenen Texte sind Gegenstand der liturgischen Feierlichkeiten zum Marientod ${ }^{39}$. Oberhalb der beiden Poeten folgt der Transport der Apostel in zwei von Engeln getragenen Wolken, zwischen denen am oberen Bildrand die Himmelspforten zu sehen sind. Die Ikonographie der Szene, wie sie Konstantin und Athanasios schufen, ist geläufig und begegnet mit geringfügigen Abweichungen in zahlreichen Denkmälern ${ }^{40}$.

Die Darstellung der Grabtragung des Leichnams (Abb. 6) gehört zu den häufig abgebildeten post mortem Ereignissen ${ }^{41}$. In dem sich nach rechts bewegenden Leichenzug wird die auf einer Bahre liegende Maria von den Aposteln getragen. Angeführt wird die Prozession von drei heiligen Bischöfen und abgeschlossen von mehreren trauernden Männern; hinter der Tragbahre schließt sich eine nach rechts bewegende Engelschar an. Vor der Bahre ist die Jephonias-Episode abgebildet: Gezeigt wird, wie dem fanatischen Juden Jephonias, der den Katafalk der Gottesmutter umstoßen wollte, vom Erzengel Michael mit einem Schwert die Hände abgeschlagen werden ${ }^{42}$. Diese Szene erscheint oft auch als Nebenmotiv in der Komposition des Marientodes vor dem Sterbebett. In mehrszenigen Koimesis-Zyklen wird die Episode allerdings der translatio zugeordnet, da sie ihr thematisch angehört ${ }^{43}$. Die älteste ostkirchliche Darstellung der Grabtragung ist auf der Bronzetür Susdal

39. Schon seit dem 11. Jahrhundert begegnen die Hymnenschreiber in der Darstellung, und auch die Hermeneia sieht sie für die Wiedergabe der Koimesis vor, J. Mysliveć, «Tod Mariens», Lexikon der christlichen Ikonographie, Band 4 (1972) Sp. 335; Johannes Damaskenos zitiert den Vers eines Heirmos, der beim Orthros des Koimesis-Festes verle-

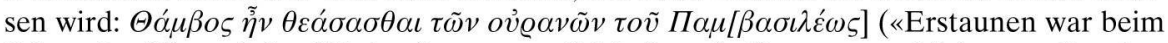
Sehen der Himmel des Königs der ganzen Schöpfung»). Kosmas von Maioumas Text bezeichnet die Ode eines Heirmos, die ebenfalls beim Orthros am 15. August gesungen wird:

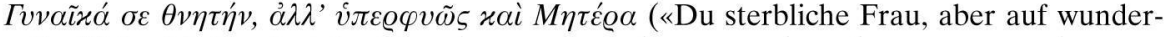

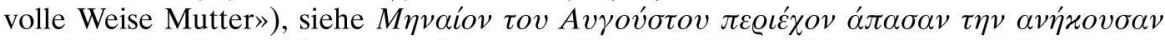

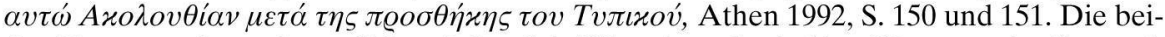
den Texte werden gelegentlich auf den Schriftbändern der beiden Hymnenschreiber aufgetragen, obwohl die Hermeneia andere Zitate vorsieht, Papadopoulos-Kerameus, op.cit., S. 144 f.

40. Siehe die Bildbeispiele bei Wratislaw-Mitrovié - Okunev, op.cit., 147-173 und Schiller, Iconographie, Bd. 4,2, op.cit., S. 348-353.

41. Schiller, Iconographie, Bd. 4,2, op.cit., S. 126-128. Zum Bildthema siehe außerdem K. Simon, «Die Grabtragung Mariä», Städel Jahrbuch 5 (1926) 75-98 mit vorwiegend abendländischen Bildbeispielen.

42. $\mathrm{Zu}$ dem Motiv, das zuerst in der Koimesis-Szene in der Panagia Mavriotissa in Kastoria (12. Jh.) belegt ist, siehe ausführlich Schiller, op.cit., S. 126f. und Kreidl-Papadopoulos, op.cit., Sp. 155. A. W. Epstein sieht in der Wiedergabe der Jephonias-Episode in der Koimesis-Darstellung ein anti-semitisches Bildelement: «Frescoes of the Mavriotissa Monastery near Kastoria: Evidence of Millenarianism and Anti-Semitism in the Wake of the First Crusade», Gesta 26,1 (1982) 21-29.

43. Kreidl-Papadopoulos, op.cit., Sp. 155. 
(1227-1237 $)^{44}$ anzutreffen, gefolgt von jener in der Peribleptoskirche in Ohrid $(1295)^{45}$. Es schließen sich diverse Illustrationen in der spätbyzantinischen Wandmalerei $\mathrm{an}^{46}$. In der nachbyzantinischen Zeit fand das Thema keinen Anklang, die Maler gaben der Szene der Grablegung Mariens den Vorzug. Kern der erhaltenen palaiologischen Darstellungen der Grabtragung ist die Bahre mit dem Leichnam der Gottesmutter, der von den Aposteln befördert wird. Aufgefüllt wird die Szenerie durch Engel und weitere, den Leichenzug begleitende Trauernde, sowie durch die Jephonias-Episode. Die Anordnung der Figuren in der Komposition kann in Korrelation zum vorgegebenen Bildfeld variieren. An der Komposition in der Athanasioskirche sticht der schwarz gefärbte Hintergrund ins Auge, wodurch dem Trauercharakter des Geschehens eine zusätzliche Intensität verliehen wird.

Die Szene der Apostel am leeren Grab in Kombination mit der leiblichen Auffahrt der Gottesmutter (Abb. 7) ist jene Darstellung, die neben der Grablegung Mariens, die in der Athanasioskirche nicht dargestellt ist, am häufigsten in Koimesis-Zyklen aufgenommen wurde ${ }^{47}$. Diese beständige Wiedergabe läßt sich dahin gehend erklären, daß die assumptio corporis bereits ab dem Ende des 13. Jahrhunderts integrales Bildelement breit angelegter KoimesisKompositionen ist und entsprechend oft Wiedergabe erfuhr. In der in einem eigenen Bildfeld eingepaßten Szene in der Athanasioskirche erscheint in der oberen Bildhälfte die in den Himmel fahrende Gottesmutter in einer von zwei schwebenden Engeln getragenen Gloriole. Von links fliegt der Apostel Thomas in einer von einem Engel geführten Wolke auf Maria zu, die ihm ihren Gürtel übergibt. Elf Jünger am leeren Grab sind in der unteren Bildhälfte in einer Landschaft positioniert. Vor ihnen ist bildparallel das leere Grab angeordnet, über das sie sich gestikulierend beugen. Bei der Gestaltung der Szene folgten die Maler einem Bildtypus, der seit der palaiologischen Epoche belegt ist und in der nachbyzantinischen Zeit weiter tradiert wurde ${ }^{48}$. Häufiger in der postby-

44. Siehe A. N. Ovchinnikov, Golden Gates in Suzdal, Moskau 1978, Abb. 49-50.

45. Siehe Hallensleben, op. cit., Skizze auf S. 70.

46. Siehe zum Beispiel die Szenen in der Pantokratorkirche in Dečani (1335-1350), siehe Lafontaine-Dosogne, op. cit., Abb. 4 sowie in Markov Manastir bei Skopje (um 1375), siehe G. Millet - A. Frolow, La peinture du moyen âge en Yougoslavie, Band 4, Paris 1969, Abb. 106 auf Taf. 53.

47. Zur Wiedergabe der Apostel am leeren Grab in der byzantinischen Wandmalerei siehe Wratislaw-Mitrović - Okunev, op.cit., S. 158-160; Hallensleben, op. cit., S. $72-75$ und Schiller, Iconographie, Bd. 4,2, op.cit., S. 119-121.

48. Eine analoge Bildformulierung begegnet zuerst in der Verkündigungs-Kirche in Gračanica (1321), siehe Petković, op.cit., Taf. 47a oder Wratislaw-Mitrović - Okunev, op. cit., Taf. IX,2. Vgl. auch die gleichartig formulierte Darstellung in der Nikolauskirche in Ljuboten bei Skopje (1337), siehe Petković, op.cit., Taf. 132a oder Wratislaw-Mitrović - Okunev, op.cit., Taf. X. In zwei gegenüberliegende Bildfelder eingepasst sind die Szenen der Auffahrt 
zantinischen Wandmalerei ist allerdings die getrennte Wiedergabe von leiblicher Auffahrt und der Apostel am leeren Grab. Dabei erscheint die Auffahrt mit der Gürtelübergabe oberhalb des Sterbebettes in Kompositionen des Marientodes, und die Jünger am leeren Grab sind meistens abgesondert am Außenrand dieser Darstellungen in einer Nebenszene wiedergegeben, wobei Thomas in beiden Komplementär-Episoden erscheint ${ }^{49}$. Seine doppelte Wiedergabe folgt den Anweisungen der Hermeneia, die vorgibt, dass Thomas bei der Auffahrt den Gürtel nimmt und dann den übrigen Aposteln am Grab zeigt ${ }^{50}$.

In der außergewöhnlichen Szene der Höllenfahrt Mariens (Abb. 8) ist die Hölle als rotes Felsmassiv gestaltet, aus dem sich zwei dunkle Höhlen öffnen. In der oberen schwebt die Gottesmutter mit empor gehaltenen Armen auf einer Wolke, die von zwei fliegenden Engeln getragen wird. Maria wendet sich nach links unten, von wo aus mehrere Köpfe von Verdammten zu ihr aufblicken. Links dieser Gruppe folgen in einem anderen Strafbezirk die Oberkörper von weiteren Verfluchten, die ihre Köpfe aus einem lodernden Feuer heraus auf die Gottesmutter richten. Die untere Öffnung der Hölle wird von zahlreichen Verdammten dominiert, die von Würmern und Schlangen umgeben sind.

Während die oben besprochenen Darstellungen des Koimesis-Zyklus auf frühen apokryphen Berichten zum Tod der Gottesmutter fußen, lässt sich für die Wiedergabe des Motivs der Höllenfahrt Mariens keine der tradierten Legendenvarianten anführen. Als prägend für die Ikonographie des Bildthemas kann dagegen ein apokrypher Text gelten, in dem ein anonymer Autor ausführlich das Hinabsteigen der Gottesmutter in die Hölle schildert. Der Bericht ist in verschiedenen Versionen in mehreren Manuskripten überliefert und trägt den Titel Die Apokalypse der allerheiligsten Gottesmutter über die

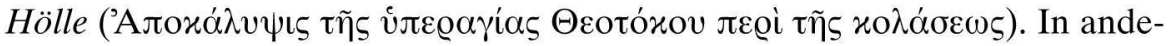
ren Fassungen wird der Text folgendermaßen benannt: Die Apokalypse der Jungfrau, die in die Hölle herabstieg und sah, wie die Sünder bestraft wurden

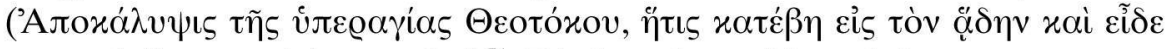

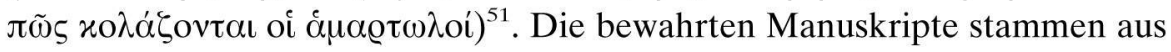

Mariens und der Apostel am leeren Grab in der Pantokratorkirche in Dečani (1335-50), siehe Lafontaine-Dosogne, op.cit., Abb. 4. Vgl. auch die analoge Bildaufteilung im Neuen Katholikon des Metamorphosis-Klosters (1552) auf Meteora, siehe M. Chatzidakis - D. Sofianos, The Great Meteoron, History and Art, Athen 1990, Abb. auf S. 117, 119 und 121.

49. Stellvertretend sei auf die Wandmalereien der Apostelkirche in Derbisiana (1764) verwiesen, siehe Konstantios, op.cit., Abb. 1.

50. Siehe Papadopoulos-Kerameus, op.cit., S. 145 und Schäfer, op.cit., S. 127.

51. Zum Text siehe M. R. James, Apocrypha anecdota. A Collection of Thirteen Apocryphal Books and Fragments, Cambridge 1893, S. 109-126; H. Pernot, «Descente de la Vierge aux Enfers d'après les manuscrits Grecs de Paris», Revue des Études Grecques 13 
der nachbyzantinischen Zeit (15.-16. Jahrhundert), gehen aber vermutlich auf einen gemeinsamen Urtext zurück, dessen Entstehung deutlich früher angesetzt wird $^{52}$.

Der unbekannte Autor berichtet, dass die Gottesmutter beim Gebet am Ölberg dem Erzengel Michael gegenüber den Wunsch äußert, in die Hölle zu fahren, um die Leiden der Verdammten, über die sie sehr bekümmert ist, mit eigenen Augen zu sehen. Daraufhin begegnet Maria «dem Engel des Herrn» und 400 weiteren Engeln, die sie unter anderem mit folgenden Worten begrüßen: «[...] Gepriesen seiest Du, die höher ist als alle, erreichend den Thron Gottes». Die Theotokos wird dann in Begleitung des Erzengels Michael durch die Hölle geführt und sieht die verschiedenen Torturen der Verdammten, die detailliert beschrieben werden. Die diversen Gruppen von Sündern sind von Dunkelheit umgeben, die durch die Anwesenheit der Gottesmutter gelüftet wird. Bei Marias Reise von einem Strafbezirk zum nächsten steigert sich ihr Mitleid zusehends, bis sie sogar Michael bittet, sie im Hades zu lassen, damit sie die Strafen der Christen teilen darf. Schließlich fährt sie von der Hölle an Gottes Thron und bittet diesen in Tränen um Barmherzigkeit für die Gepeinigten. Sie sagt, dass sie die Höllenstrafen gesehen hat und die Leiden jener, die sie preisen nicht mehr ertragen kann. Darauf hin entgegnet ihr Gott: «Hör, Allerheiligste, keinem, der dich anruft, wird sein Ansinnen versagt, weder im Himmel noch auf Erden; er wird durch Dich gerettet werden». «Für die Liebe meiner unbefleckten Mutter», sagt er «gewähre ich den Sündern Ruhe vom Tag meiner Auferstehung bis Allerheiligen ${ }^{53}$. Daraufhin wird Maria ins Paradies geleitet, wo sie sich an die Seite der Gerechten begibt, und die Engel den Aposteln berichten, was sie Maria in der Hölle gezeigt haben ${ }^{54}$.

Ein Vergleich des Textes mit der Wiedergabe der Höllenfahrt Mariens

(1900) 233-257; H. Müller, «Die Offenbarung der Gottesmutter über die Höllenstrafen. Theologischer Gehalt und dichterische Form», Die Welt der Slaven 6 (1961) S. 26-39; G. Galavaris, «Mary's Descent into Hell: A Note on the Psalter Oxford, Christ Church Arch. W. Gr. 61», Byzantine Studies-Études Byzantines 4,2 (1977) S. 189-194; A. Semoglou, Le voyage outre-tombe de la Vierge dans l'art byzantin. De la descente aux enfers à la montée au ciel, Thessaloniki 2003, S. 115-125 mit zahlreichen Verweisen auf die ältere Literatur.

52. Pernot, op.cit., 238 und Galavaris, op.cit., S. 190 vermuten die mittelbyzantinische Periode als Entstehungszeit des Urtextes. Dagegen siedelt Mimouni die Schrift bereits im 5. Jahrhundert an: S. C. Mimouni, «Les Vies de la Vierge: état de la question, Apocrypha», Revue Internationale des Littératures Apocryphes 5 (1994) 101-112 bes. S. 108.

53. Gemeint ist die Zeit von Ostersonntag bis zum ersten Sonntag nach Pfingsten, an dem die Ostkirche aller Heiligen gedenkt.

54. Den griechischen Text in voller Länge geben Pernot, op.cit., 239-256 und Semoglu, op.cit., S. 115-125. Pernot, op.cit., 234-237, hat eine französische Zusammenfassung des Wortlautes angefertigt, einen englischen Abriss des Textes liefert Galavaris, op.cit., S. 191. 
zeigt, dass die Formulierung des Bildthemas zweifellos von den Ausführungen des anonymen Autors inspiriert sind. Die Darstellung zeigt die Reise der Gottesmutter durch die Hölle, wobei sie sich einer Gruppe von Verdammten entgegenneigt, deren Leiden sie aufgewühlt zu haben scheinen. Eine ähnliche Darstellung schufen Konstantin und Athanasios in ihren wesentlich später entstandenen Fresken im Xeropotamou-Kloster auf dem Berg Athos (1783). Dort begegnet die Szene in einer Lünette als Einzeldarstellung über einem Türsturz im Katholikon und ist nicht Bestandteil eines Marienzyklus (Abb. 11). Abgebildet ist die Gottesmutter in einer Gloriole, die von mehreren Engeln flankiert wird ${ }^{55}$. Maria und die Engel schweben auf einem Wolkenband, unter dem sich von links nach rechts drei voneinander abgetrennte Höllenbezirke öffnen. Während der mittlere Bereich als dunkle monochrome Fläche gestaltet ist, sind in den beiden äußeren Feldern Verdammte zu sehen, die an Seilen aufgehängt sind.

Die beiden Höllenfahrt-Darstellungen machen deutlich, dass den Malern das Bildthema in mindestens zwei Varianten geläufig war. Eine dritte Formulierung des Sujets aus dem 18. Jahrhundert kann in einer bulgarischen Buchmalerei mit dem Leben von Basileios dem Jüngeren angetroffen werden. In einer Miniatur des Manuskriptes ist die Gottesmutter in Begleitung von zwei Engeln stehend auf einem Felsmassiv abgebildet (Abb. 12) ${ }^{56}$. Die drei Figuren neigen sich nach unten, wo sich in dem Felsen eine dunkle Höhle öffnet, in der zahlreiche Verdammte zu sehen sind. Die meisten von ihnen erleiden ihre Qualen in einem Meer von Flammen, das sich im unteren Bereich der Öffnung ausbreitet. Über dem Feuermeer schließen sich einige weitere gefesselte Figuren an, die an Gestängen hängen.

Die drei oben beschriebenen Abbildungen zeigen die Fahrt der Gottesmutter in die Hölle bei der Betrachtung der Leiden beziehungsweise beim Besuch der Verdammten an den Orten ihrer Bestrafung. Ihnen gehen diverse mittelalterliche Darstellungen voraus, die verdeutlichen, dass die Vorstellung von der Hadesfahrt Mariens aber schon länger verbreitet war. Allerdings schildern diese das Thema auf eine abweichende Art und Weise. Zu erwähnen ist zunächst ein Relief auf einem Kapitell, das um 1170 für die Kreuzfahrerkirche der Verkündigung in Nazareth geschaffen wurde. Die Bildhauerarbeit zeigt die gekrönte Gottesmutter, die eine nimbierte Gestalt - wahrscheinlich einen Apostel - am Handgelenk durch die Hölle zieht; flankiert wird die Figurengruppe von zwei Dämonen ${ }^{57}$. Eine verwandte byzantinische

55. Siehe Tsigaras, op.cit., S. 164 mit Abb. 141.

56. Moskau, Historisches Museum, Handschriftenabteilung, muz. 350, 1. 147; M. V. Ščepkina, Bolgarskaja miniatjura XIV veka, Moskau 1963, S. 162 mit Abb. auf S. 158.

57. Zu der Darstellung auf dem Kapitell siehe ausführlich J. Folda, The Nazareth Ca- 
Abbildung kann in einem Psalter in Oxford (Christ Church, cod. gr. 61) angetroffen werden, der 1391 gefertigt wurde. Auf fol. 102v des Manuskriptes ist die Gottesmutter wiedergegeben, die einen Mönch, der inschriftlich mit dem Namen Kaloeidas bezeichnet ist, am Handgelenk aus einem Sarkophag zieht. Maria führt ihn Christus entgegen, der thronend und segnend auf der gegenüberliegenden Miniatur (fol. 103r) gezeigt wird ${ }^{58}$. Als weitere Illustration des Themas folgen zwei spätmittelalterliche Darstellungen, die auf einer russischen Ikone des beginnenden 15. Jahrhunderts begegnen, die im Moskauer Kreml aufbewahrt wird ${ }^{59}$. Auf der Tafel sind Szenen wiedergegeben, welche die ersten elf Strophen des Akathistos-Hymnos bebildern. Diesen Hymnos-Illustrationen sind begleitend einige Szenen anderer Thematik hinzugefügt, von denen zwei aufeinander folgende die Hadesfahrt der Gottesmutter schildern. In beiden Darstellungen steht Maria auf einem Suppedaneum vor der Hölle, die sich als dunkle Höhle in einem Gebirgsmassiv öffnet. In der ersten Szene zieht sie den im Hades knienden Adam am Handgelenk aus der Unterwelt, während sie in der zweiten Eva auf analoge Weise der Hölle entreißt ${ }^{60}$.

Als Textquelle für die soeben angeführten mittelalterlichen Darstellungen kommt ebenfalls der oben beschriebene anonyme Bericht über die Höllenfahrt Mariens in Betracht ${ }^{61}$. Bedeutsam ist, dass das Motiv des Herabsteigens der Gottesmutter in die Hölle aus unterschiedlichen Regionen überliefert ist und sowohl im byzantinischen wie im slawischen Bereich bekannt war. Dieses Phänomen lässt trotz der wenigen erhaltenen Bildbeispiele auf eine weite Verbreitung des Textes der Hadesfahrt der Theotokos schließen ${ }^{62}$.

Was die Ikonographie dieser mittelalterlichen Abbildungen betrifft, so ist festzustellen, dass diese unzweifelhaft dem Bildtypus der Höllenfahrt Christi (Anastasis) entlehnt ist. Dabei entspricht die Haltung und Gestik der Gottesmutter jener des in die Hölle fahrenden Christus, der Adam am Handgelenk der Unterwelt entreißt ${ }^{63}$. Die Ikonographie dieser Darstellungen unter-

pitals and the Crusader Shrine of the Annunciation, University Park-London 1986, S. 43-50 mit Taf. 26-31 sowie Semoglu, op.cit., S. 81f. mit Taf. 46.

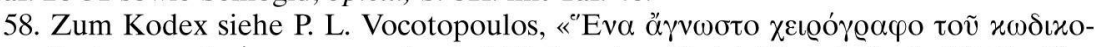

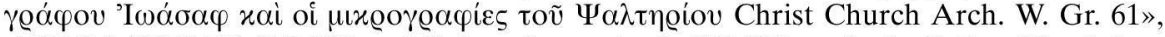
$\triangle X A E 8$ (1975/76) 179-198 und Galavaris, op.cit., S. 189-194 sowie A. Cutler, The Aristocratic Psalters in Byzantium, Paris 1984, S. 111 Kat.-Nr. 55 mit der älteren Literatur.

59. Zu der Ikone siehe jüngst ausführlich Spatharakis, op. cit., S. 98-106 mit zahlreichen Abbildungen.

60. Spatharakis, op.cit., Abb. 253, 255 und 256.

61. Vgl. Galavaris, op.cit., S. 190-192; Folda, op.cit., S. 46; Spatharakis, op.cit., S. $100 f$.

62. Vgl. Galavaris, op.cit, S. 192; Spatharakis, op.cit., S. 101.

63. Folda, op.cit., S. 45; Galavaris, op.cit., S. 191. Zur Darstellung der Höllenfahrt Christi und ihrer Genese siehe ausführlich A. Kartsonis, Anastasis. The Making of an Image, Princeton, New Jersey 1986. 
scheidet sich damit von den drei oben beschriebenen Abbildungen der Hadesfahrt Mariens aus dem 18. Jahrhundert. Demgemäß ist davon auszugehen, dass die postbyzantinischen Darstellungen der Höllenfahrt der Gottesmutter nicht auf den älteren mittelalterlichen Bildformulierungen fußen. Genau genommen liegen den mittelalterlichen und nachbyzantinischen Bildschöpfungen der Hadesfahrt Mariens auch nicht dieselben Ideen zugrunde. Denn in den älteren Bildbeispielen führt oder zieht Maria eine Begleitfigur durch oder aus der Hölle, während sie bei den späteren Formulierungen in Begleitung von Engeln die Qualen der Verdammten in den Strafbezirken schaut.

Eine Frage, die sich aus den oben gemachten Ausführungen erhebt, ist, an welchen ikonographischen Vorlagen die nachbyzantinischen Darstellungen der Höllenfahrt Mariens anknüpfen. Die bislang bekannten Beispiele sind im 18. Jahrhundert oder später entstanden ${ }^{64}$. Dabei bildet die Abbildung in der Athanasioskirche (1744) nach heutiger Kenntnis des Denkmälerbestandes den Beginn der chronologischen Reihe. Obwohl die Darstellung derzeit als die älteste gelten kann, ist weniger davon auszugehen, dass Konstantin und Athanasios diesen Bildtypus erschufen. Sie knüpften vermutlich an ältere Vorlagen an, die entweder verloren gegangen oder noch nicht durch die wissenschaftliche Literatur erschlossen sind. Unter Umständen kamen die Maler auf dem Berg Athos mit dem Sujet in Berührung, wo eventuell verwandte Darstellungen existieren, deren Veröffentlichung noch aussteht. Zumindest ist an den bislang bekannten Illustrationen des Themas ablesbar, dass es im 18. Jahrhundert in mehreren ikonographischen Varianten vorlag, was für eine gewisse Verbreitung des Sujets spricht.

Unzweifelhaft kommt dem Thema der Höllenfahrt Mariens eine soteriologische Bedeutung zu. Denn die Gottesmutter ist diejenige, die großes Mitleid für die gepeinigten Seelen in der Hölle empfindet und am Thron Gottes als Mediatrix für die Sünder eintritt. In ihrer Einzigartigkeit leistet sie Fürbitte, denn sie ist diejenige, die höher als alle anderen am Thron Gottes steht und Rettung aus der Dunkelheit der Hölle erwirken kann. Generell kommt ihr als Fürsprecherin für die gesamte Schöpfung eine besondere Dimension zu, da sie die Himmelsleiter ist, die den Weg der Menschen zu Gott ebnet, wodurch ihnen Erbarmen gewährt wird ${ }^{65}$.

Die Höllenfahrt Mariens verfügt über einen ähnlichen soteriologischen Inhalt wie die Höllenfahrt Jesu, bei der Christus die Gerechten des Alten Testaments dem Hades entreißt. Bedeutsam ist in diesem Zusammenhang, dass

64. Semoglou, op.cit., S. 82f. verweist noch auf eine armenische Mitra, die 1802 gefertigt wurde, und das Thema zeigen soll.

65. Die Interpretation Mariens als Himmelsleiter wird besonders in den Gesängen des Akathistos-Hymnos deutlich, siehe dazu ausführlich Kalokyres, op.cit., S. 58. 
beide Bildthemen in der Athanasioskirche so positioniert sind, dass sie beim Eintritt in die Kirche von den Gläubigen in einer Art Zusammenschau wahrgenommen werden können. Während die Szene der Höllenfahrt Mariens auf der Nordwand des Mittelschiffs lokalisiert ist, wurde die Darstellung der Anastasis rechts oberhalb von ihr an der Nordwand des nördlichen Seitenschiffes angebracht. Damit sind beide Szenen direkt gegenüber dem Eingang positioniert, und durch die bildliche Verknüpfung der Themen wird den Eintretenden in den Kirchenraum nachhaltig ihre Errettung durch Christus und seiner Mutter in Aussicht gestellt.

Direkt oberhalb der Höllenfahrt Mariens schließt sich im Gewölbe die Darstellung des Kindermordes zu Bethlehem an (Abb. 9). Die Wiedergabe des Bildthemas in Verbindung mit dem Koimesis-Zyklus bezeugt eine außergewöhnliche Zusammenstellung, denn in der Regel ist der in den nachbyzantinischen Monumentaldekorationen häufig abgebildete Kindermord in die Illustrationsfolgen der Festbildzyklen aufgenommen worden, in denen er zwischen den Szenen der Geburt Jesu und seiner Darbringung im Tempel eingeschoben ist ${ }^{66}$. Ferner begegnet das Thema in Bildsequenzen, die sich der Kindheit des Gottessohnes widmen ${ }^{67}$. Bei der Aufnahme der Szene in den Zyklus zum Todesgeschehen der Gottesmutter scheint es sich nicht um eine Verlegenheitslösung zu handeln, denn es hätten sich weitere Darstellungen zum Ableben Mariens, wie beispielsweise ihre Grablegung oder ihre Krönung zur Himmelskönigin ${ }^{68}$ angeboten, die in der nachbyzantinischen Malerei oft wiedergegeben sind. Die Maler gaben aber stattdessen der Szene des Kindermords in Bethlehem den Vorzug.

Die Darstellung des Kindermords (Mt 2,16-18) in der Athanasioskirche knüpft an tradierte Bildformulierungen an, die im Wesentlichen aus folgenden drei Bestandteilen bestehen: aus Herodes, der den Befehl zum Morden gibt; aus den Knechten des Königs, die im Begriff sind, die Kinder zu ermorden oder die bereits getöteten Herodes vorweisen; und aus den Müttern, die versuchen,

66. Ein Beispiel bietet das Freskenprogramm der Metamorphosis-Kirche in Veltsista (1568) in Epirus, siehe A. Stavropoulou-Makri, Les peintures murales de l'église de la Transfiguration à Veltsista (1568) en Epire et l'atelier des peintres Kondaris, Ioannina ${ }^{2} 2001$, S. $47-$ 49 mit Abb. 14b.

67. So beispielsweise in den Wandmalereien des Philanthropinon-Klosters in Ioanni-

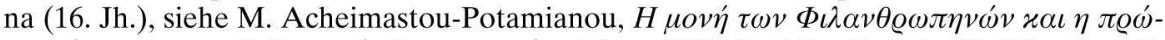

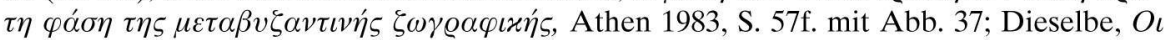

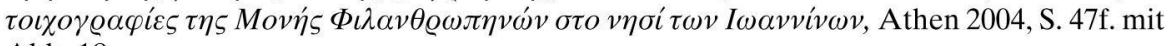
Abb. 18.

68. Die Darstellung der Krönung Mariens fand stattdessen Aufnahme in das Bildprogramm des Sanktuariums, wo sie neben Szenen der Wundertaten Christi im zentralen Gewölbe des Bemas illustriert ist. 
ihre Kinder zu schützen oder, wenn sie ihnen entrissen sind, wehklagen ${ }^{69}$ Häufig ist in die Darstellung - wie hier - die apokryphe Episode der Flucht Elisabeths mit dem Johannesknaben (PsJac 22, 1-3) als Nebenszene integriert ${ }^{70}$.

Unterhalb der figurenreichen Komposition des Kindermordes schließt sich links der Szene der Höllenfahrt Mariens auf einem Bogenfeld die Einzeldarstellung des Propheten Jeremias an. Der Prophet wendet sich nach rechts und zeigt auf einen Rotulus, den er in der linken Hand hält (Abb. 8). Auf dem Schriftband wird Jer 31, 15 beziehungsweise Mt. 2, 18 paraphrasiert: „Eine Stimme hört man in Rama, Klagen und Weinen, und große Trauer" ${ }^{\text {"71 }}$. Der Text begegnet wiederholt in Verbindung mit der Darstellung des Kindermordes und rekurriert auf das Klagen der Stammutter Rahel, die den Verlust ihrer Kinder beweint und keinen Trost annehmen will ${ }^{72}$. Dabei gilt der Kindermord, der bei Mt 2, 16-18 geschildert wird, als die Erfüllung der Weissagung von Jer $31,15^{73}$.

Aus welchen Motiven die Szene des Kindermordes dem Koimesis-Zyklus beigeordnet wurde, kann vorläufig nicht beantwortet werden. Dagegen scheint die Wiedergabe des Christus Anapeson (Abb. 10) zwischen der Szene der Todesankündigung und der Versammlung der Apostel offenbar durch tradierte Plazierungsgewohnheiten angeregt $\mathrm{zu} \mathrm{sein}^{74}$. Es ist davon auszuge-

69. Zur Ikonographie der Darstellung siehe G. Millet, Recherches sur l'iconographie de l'évangile aux XIVe, XVe et XVIe siècles d'après les monuments de Mistra, de la Macédoine et du Mont-Athos, Paris ${ }^{2}$ 1960, S. 158-163; G. Schiller, Ikonographie der christlichen Kunst. Band 1, Inkarnation - Kindheit - Taufe - Versuchung - Verklärung - Wirken und Wunder Christi, Gütersloh 1966, S. 124-126 (im Folgenden: Iconographie, Bd. 1); O. A. Nygren, «Kindermord, bethlehemitischer», Lexikon der christlichen Ikonographie, Band 2 (1972) Sp. 509-513. Zur den nachbyzantinischen Darstellungen des Kindermords und ihre Beeinflussung durch die abendländische Ikonographie der Renaissance siehe ausführlich A. Stavropoulou-Makri, «Le thème du Massacre des Innocents dans la peinture post-byzantine et son rapport avec l'art italien renaissant», Byzantion 60 (1990) 366-381 mit zahlreichen Verweisen auf die ältere Literatur zum Thema (im Folgenden: «Le thème du Massacre des Innocents»).

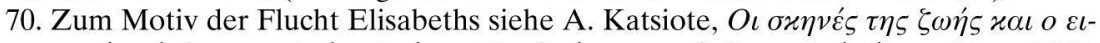

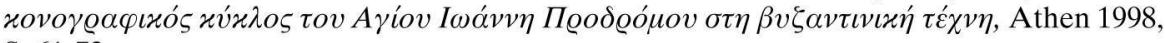
S. 61-72.

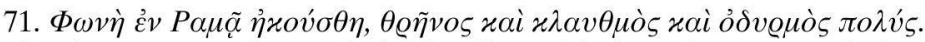

72. Ein repräsentatives Beispiel für die Verbindung des Textes mit dem Kindermord bietet die Szene im Metamorphosis-Kloster (1552) auf Meteora, siehe Chatzidakis - Sofianos, op.cit., Abb. auf S. 125. Im Freskenprogramm in Markov Manastir bei Skopje (um 1375) ist die Abbildung der klagenden Rahel inmitten ihrer Kinder unmittelbar in die Komposition des Kindermordes eingebunden worden, siehe Stavropoulou-Makri, «Le thème du Massacre des Innocents», op.cit., Abb. 5.

73. Schiller, Iconographie, Bd. 1, op.cit., S. 124.

74. Zur Ikonographie und Bedeutung des Christus Anapeson in der ostkirchlichen Kunst siehe ausführlich D. I. Pallas, Die Passion und Bestattung Christi in Byzanz. Der Ritus - das Bild, München 1965, S. 184-196; K. Wessel, «Christusbild», Lexikon zur byzantinischen Kunst, Band 1 (1966) Sp. 1011f.; E. Lucchesi Palli, «Christus-Sondertypen», Lexi- 
hen, daß das Christusbild an diesem Platz lokalisiert wurde, weil er der bevorzugte Ort für die Illustration des Themas ist. Die Darstellung des ruhenden Christusknaben ist regelmäßig über den Türen von Ausgängen anzutreffen, wobei sich das Tympanon oder der Türsturz über dem Durchgang vom Naos zum Narthex als der beliebteste Ort erweist ${ }^{75}$. Auch in der Hermeneia ist dieser Platz im Kirchenraum für die Anbringung des Anapeson vorgesehen ${ }^{76}$.

Belegt ist das symbolische Christusbild Anapeson (der Niedergefallene) seit der spätbyzantinischen $\mathrm{Zeit}^{77}$, wobei sich mehrere ikonographische Varianten für die Wiedergabe des Sujets herausgebildet haben ${ }^{78}$. In der Athanasioskirche ist eine erweiterte Form anzutreffen, in welcher der mit offenen Augen auf einer Kline ruhende Christusknabe von zwei Nebenfiguren flankiert wird. Links von Jesus wurde seine Mutter plaziert, die sich ihrem Sohn betend entgegenneigt; rechts von Christus tritt ein Engel heran, der sich dem Liegenden entgegenneigt und ein Rhipidion hält.

Textgrundlage für die Ikonographie des Christusbildes ist neben Gen 49, 9 («Wie ein Löwe hat er sich hingestreckt und wie eine Löwin sich gelagert. Wer will ihn aufstören?») Psalm 121, 4 («Siehe, der Hüter Israels schläft noch schlummert nicht.»). Außerdem gelten die Ausführungen im Löwenkapitel des «Physiologos» als wichtige Inspirationsquelle für die Abbildung Jesu als «Nichtschlafendes Auge» ${ }^{79}$. In diesem, auf spätantiker Zeit fußenden populären Volksbuch mit Abhandlungen über die Charaktere von Tieren, Bäumen und Steinen, wird der Löwe im ersten Kapitel als König der Tiere beschrieben ${ }^{80}$. Unter Anknüpfung an Gen 49, 9 und Psalm 121, 4 sind die Eigen-

kon der christlichen Ikonographie, Band 1 (1972) Sp. 396-398; B. Todić, «Anapeson. Iconographie et signification du thème», Byzantion 64 (1994) 134-165; E. Haustein-Bartsch, " "Siehe, der Hüter Israels schläft noch schlummert nicht". Zur Ikonographie des "Nichtschlafenden Auges" in der Kunst des christlichen Ostens», in: K. Ch. Felmy - E. HausteinBartsch (Hrsg.), «Die Weisheit baute ihr Haus». Untersuchungen zu hymnischen und didaktischen Ikonen, München 1999, S. 213-250 mit Hinweisen auf weitere Literatur.

75. Haustein-Bartsch, op.cit., S. 230f. mit zahlreichen Beispielen für die Wiedergabe.

76. Papadopoulos-Kerameus, op.cit., S. 219f.; Schäfer, op.cit., S. 182.

77. Als bislang älteste erhaltene Darstellung in der Wandmalerei gilt jene in der Omorphe Ekklesia in Athen, die an das Ende des 13. Jahrhunderts datiert wird, siehe A.

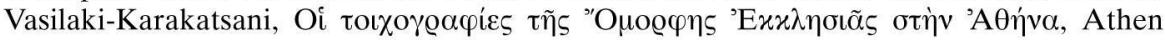
1971, S. 68-71 mit Taf. 43b und 46 sowie Todić, op.cit., Abb. 2. Nach Pallas, op.cit., S. 194, kommt die zweite Hälfte des 11. Jahrhunderts als Entstehungszeit für die Erschaffung des Christus Anapeson in Betracht.

78. Haustein-Bartsch, op.cit., S. 220-230.

79. Daneben gelten auch verschiedene liturgische Texte, die während der Fastenzeit verlesen werden, als Inspirationsquelle für die Darstellung. Zu den Texten und ihren Einfluss auf die Darstellung siehe ausführlich Haustein-Bartsch, op.cit., S. 214-219 mit Quellenangaben.

80. Physiologos, Naturkunde in frühchristlicher Deutung, aus dem griechischen übersetzt von U. Treu. Hanau ${ }^{3} 1998$, S. 5-8. 
schaften des Löwen auf den Tod und die Auferstehung Jesu bezogen. Als eine der Eigenarten des Löwen wird dargelegt, dass seine Augen im Schlaf wachend offen bleiben würden, so wie der Körper Christi am Kreuz geschlafen, seine Gottheit aber gewacht hätte. Als weitere Besonderheit ist herausgestellt, dass die Löwin ihre Jungen zunächst tot zur Welt bringe, diese aber am dritten Tage durch das Anhauchen ihres Vaters zum Leben erweckt würden, so wie der tote Jesus am dritten Tag durch seinem Vater erweckt wurde ${ }^{81}$. Das tote Löwenjunge wird also mit dem im Todesschlaf verharrenden Jesus nach seinem Kreuzestod parallelisiert. Analog zu diesem Vergleich ist mit dem Anapeson nicht nur der mit offenen Augen wachende Christus gemeint, sondern auch der im Todesschlaf befindliche.

Die Anbringung des Christusbildes über dem Ausgang an der Westwand vieler orthodoxer Kirchen ist dahin gehend begründet worden, dass dem Anapeson durch den Vergleich mit dem wachsamen Löwen eine Schutzfunktion für den Eingangsbereich zukomme. Ähnlich wie die Figuren der Erzengel neben der Türe als Wächter postieren würden, könnte mit der Wiedergabe des wachenden, nichtschlafenden Christus an dieser Stelle eine Art Hüterfunktion verbunden gewesen $\operatorname{sein}^{82}$. Es ist nicht ausgeschlossen, dass die regelmäßige Abbildung des Christusbildes über dem Eingang tatsächlich durch diese Gedanken angeregt wurde. Es sollte aber zusätzlich bedacht werden, dass mit der Darstellung des Anapeson auch jener Christus gemeint ist, der sich im Todesschlaf befindet. Entsprechend könnte seine Wiedergabe über dem Türsturz an der Westwand dahin gehend motiviert sein, seine räumliche Nähe zur Komposition des Marientodes zu evozieren, denn sowohl in der Szene der Koimesis wie in dem Bild des Anapeson spielt das Thema des Todesschlafs die vordringliche Rolle: Während die Darstellung des Anapeson den im Todesschlaf befindlichen Gottessohn zeigt, wird die Gottesmutter beim Entschlafen wiedergegeben. Diese bildimmanente Übereinstimmung lässt darauf schließen, dass von einer beabsichtigten Übereinanderstellung von Christus Anapeson und der Koimesis Mariens ausgegangen werden $\mathrm{kann}^{83}$.

Zusammenfassend lässt sich für den Koimesis-Zyklus in der Athanasioskirche festhalten, dass dieser aufgrund seiner narrativen Breite in der nach-

81. Ebenda, S. 6.

82. So z. B. Haustein-Bartsch, op.cit., S. 220-222 und 230f.

83. Vgl. E. Lucchesi Palli, op.cit., Sp. 398, die bereits die Vermutung äußerte, dass mit der Positionierung des Anapeson unter der Szene der Koimesis eine beabsichtigte Übereinanderstellung der beiden Themen veranlasst werden sollte.

Abbildungsnachweise*:

Abb. 1-10: Photos Karin Kirchhainer. - Abb. 11: Repro nach Tsigaras (op.cit. in Anm. 54) Abb. 141. - Abb. 12: Repro nach Ščepkina (op.cit. in Anm. 55) Abb. S. 158. 
byzantinischen Malerei eine Seltenheit darstellt. Zwar hatte sich für fast alle in den Zyklus aufgenommene Darstellungen bereits seit der spätbyzantinischen Zeit eine konstante Ikonographie herausgebildet, doch erfuhren nicht alle Szenen eine kontinuierliche Verbreitung bis in die nachbyzantinische Zeit hinein. Ausführliche Zyklen zum Marientod sind in der postbyzantinischen Wandmalerei nicht bewahrt, es begegnen nur vereinzelt zwei Begleitszenen innerhalb der Koimesis-Kompositionen. Entsprechend kam es zu keiner beständigen Abbildung der meisten Nebenereignisse um den Tod der Gottesmutter. Der achtszenige Entschlafen-Zyklus in der Athanasioskirche bildet folglich in seiner Ausführlichkeit eine Besonderheit in der nachbyzantinischen Kunst. Dabei kann die Frage, an welchen Vorlagen sich die Maler bei der Erschaffung des Zyklus angelehnt haben, vorläufig noch nicht beantwortet werden. Weniger wahrscheinlich ist, dass sich Konstantin und Athanasios bei der Konzeption der Bildfolge an die mittelalterlichen Koimesis-Zyklen der serbischen Monumentalmalerei orientiert haben. Vielmehr ist davon auszugehen, dass auch in der nachbyzantinischen Zeit einige breiter angelegte Bildfolgen zum Entschlafen der Gottesmutter existierten, die entweder nicht mehr erhalten sind, oder deren Publikation noch aussteht. Möglicherweise kamen die Maler auf dem Berg Athos oder in anderen Regionen, in denen sie tätig waren, mit ausführlicheren Bildsequenzen zum Todesgeschehen Mariens in Berührung, nach deren Vorlagen sie arbeiteten.

KARIN KIRCHHAINER 


\section{ПЕРІАНЧH}

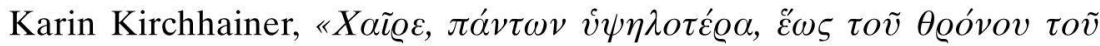

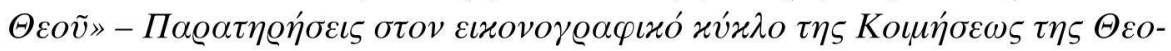

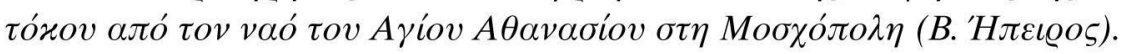

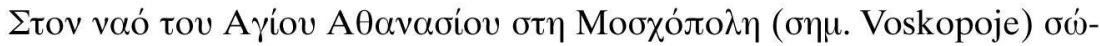

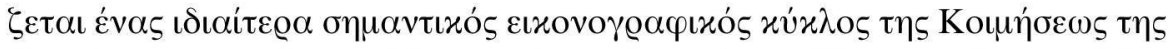

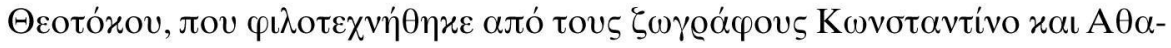

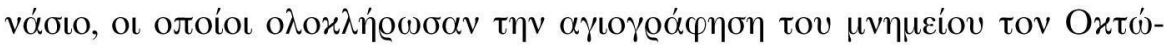

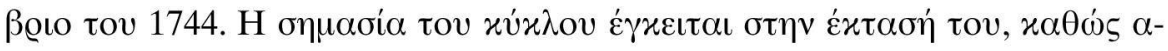

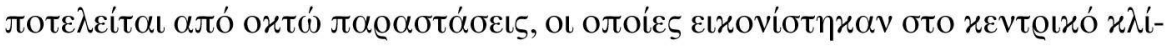

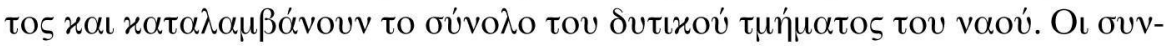

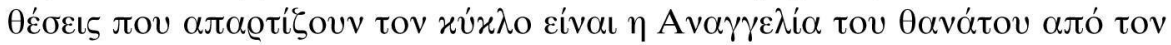

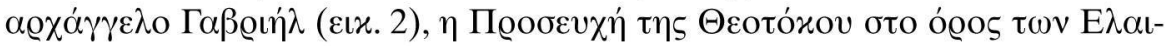

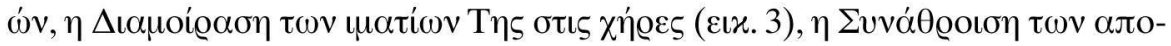

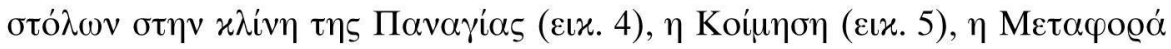

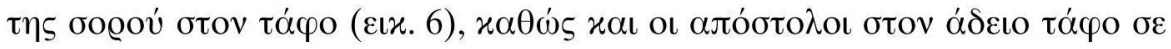

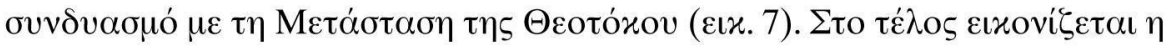

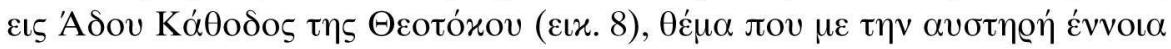

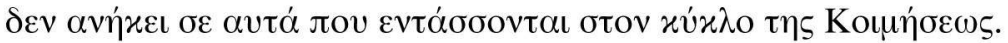

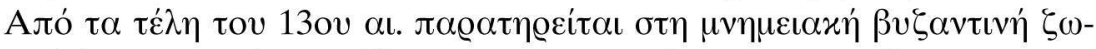

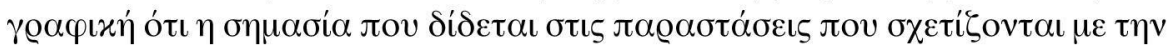

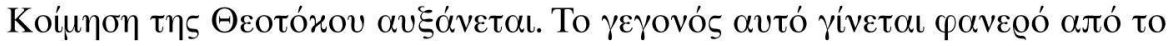

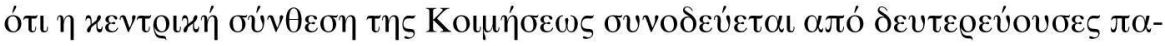

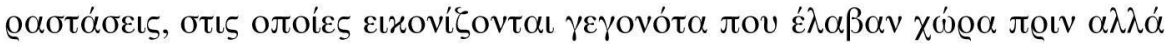

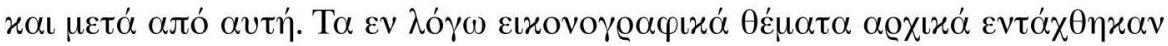

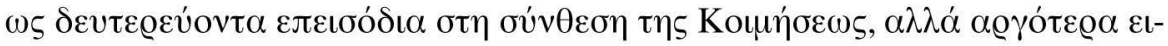

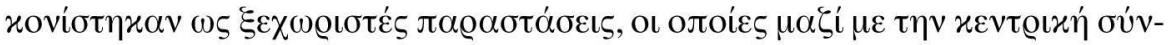

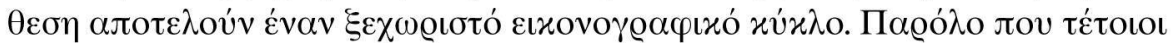

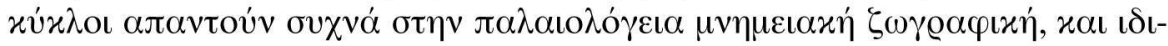

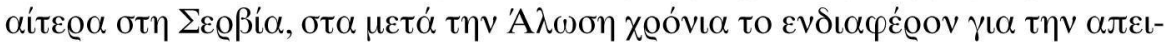

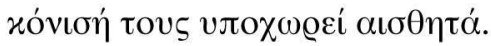

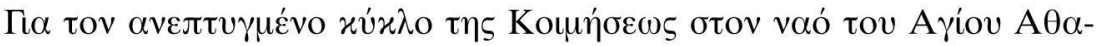

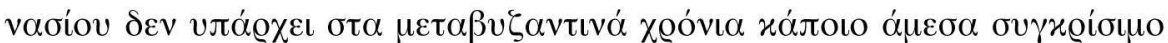

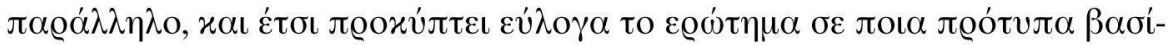

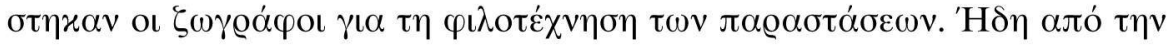




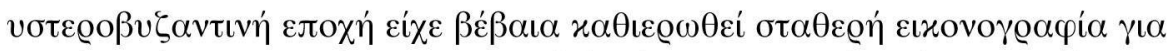

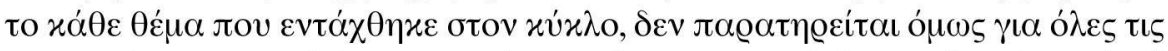

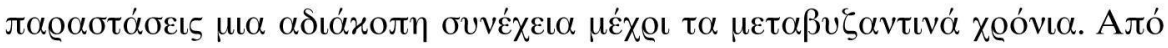

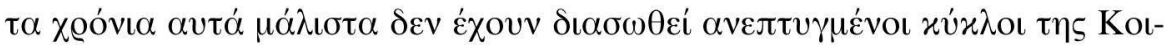
$\mu \eta \dot{\sigma \varepsilon \varepsilon \omega s . ~ A v \tau i \theta \varepsilon \tau \alpha ~ \alpha \pi \alpha v \tau o u ́ v ~ \mu \varepsilon \mu o v \omega \mu \varepsilon ́ v \alpha ~ \varepsilon л \varepsilon เ \sigma o ́ \delta ı, ~ \tau \alpha ~ о л о і ́ \alpha ~ x \alpha \tau \alpha ́ ~ x a v o ́ v \alpha ~}$

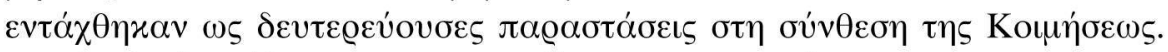

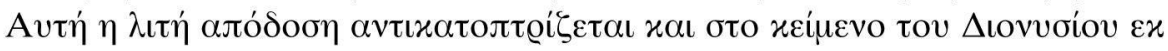

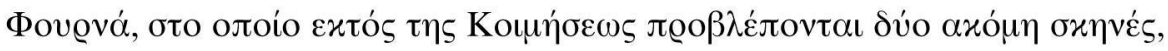

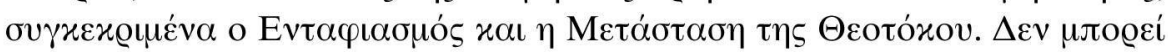

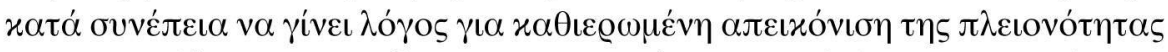

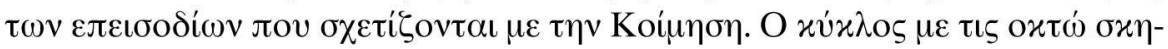

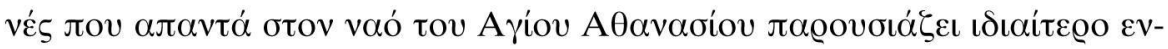

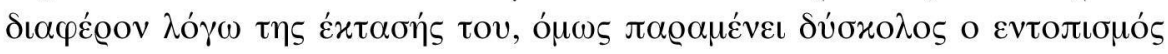

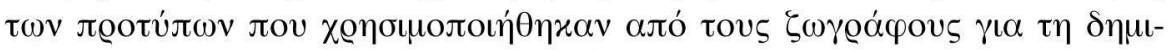

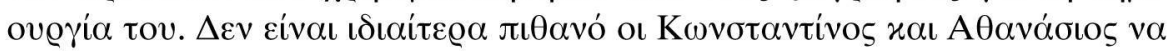

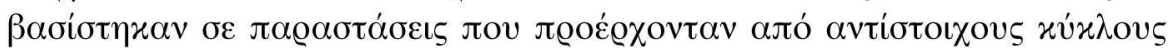

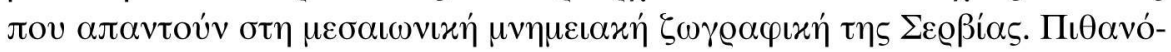

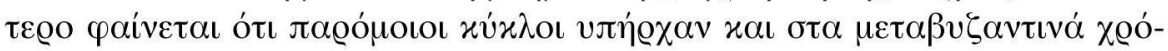

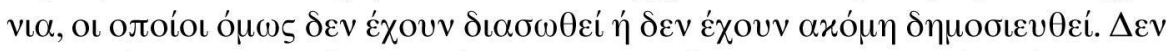

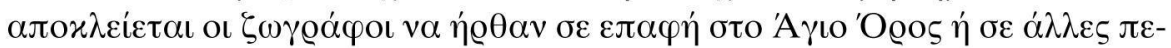

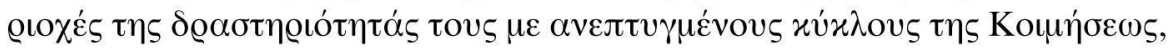

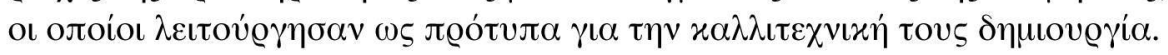




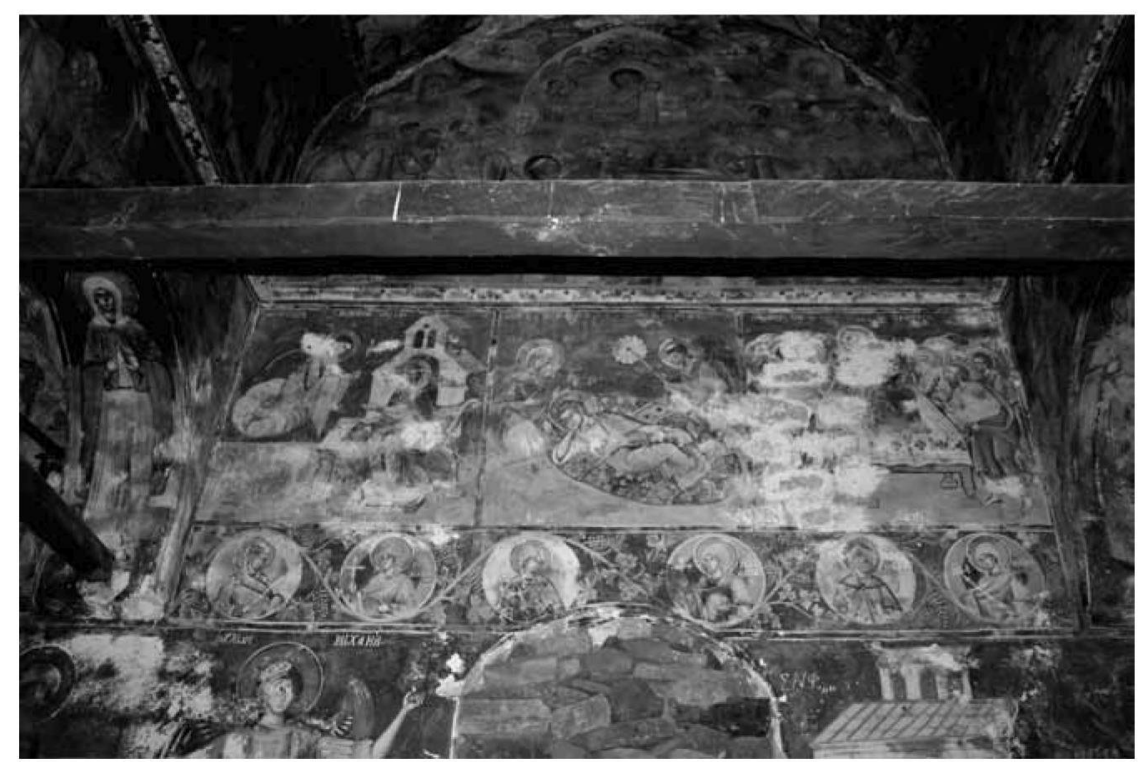

Abb. 1: Voskopoje, Athanasioskirche, Westwand.

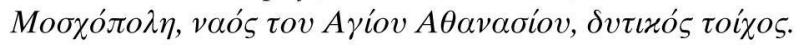

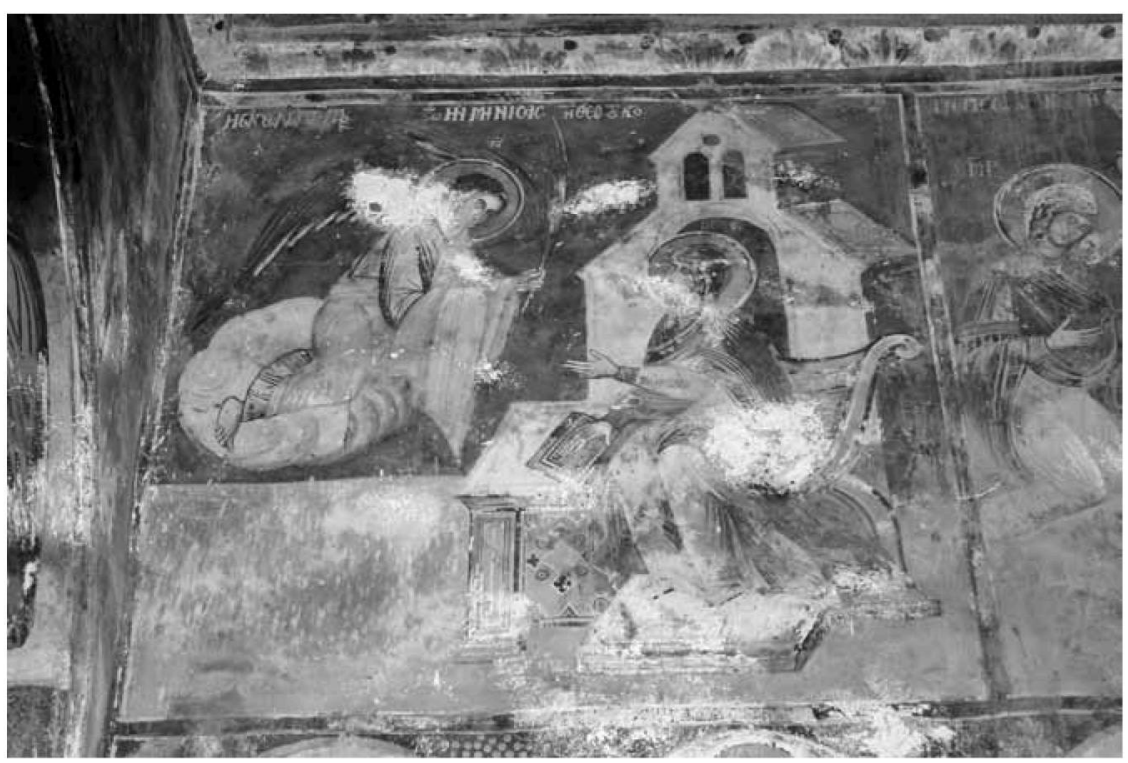

Abb. 2: Voskopoje, Athanasioskirche, Todesankündigung an Maria.

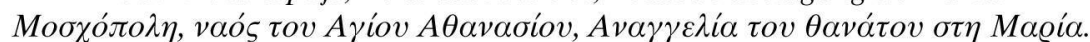




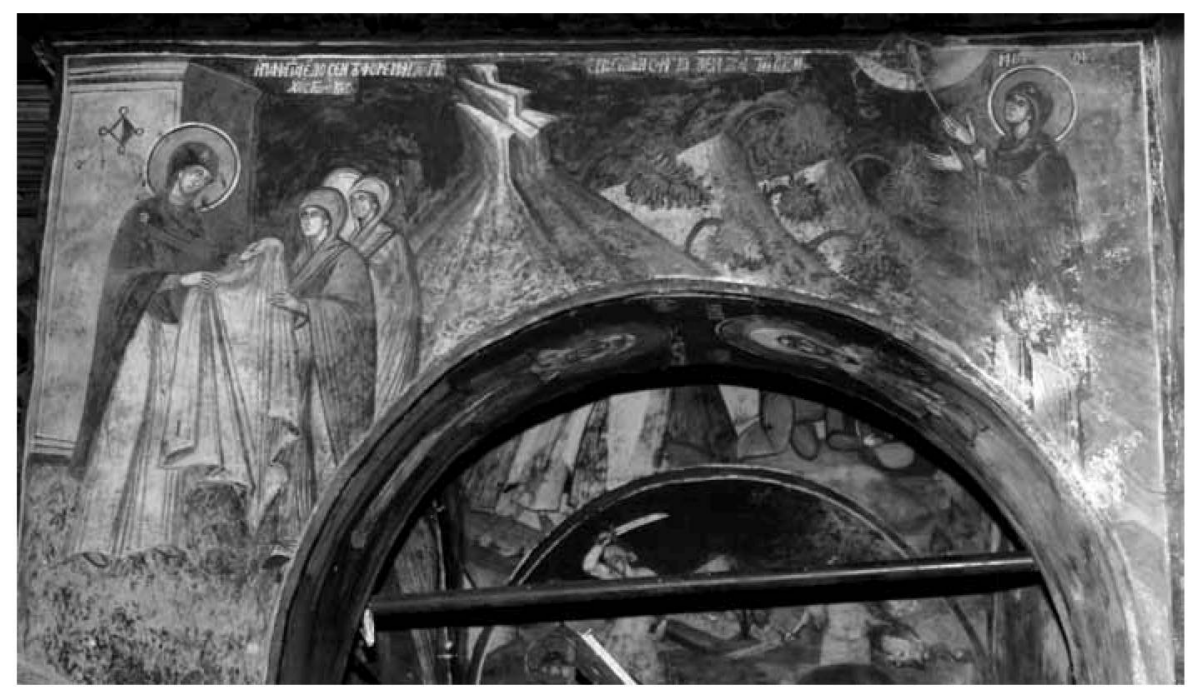

Abb. 3: Voskopoje, Athanasioskirche, Gebet Mariens am Ölberg, Verteilung der Kleider.

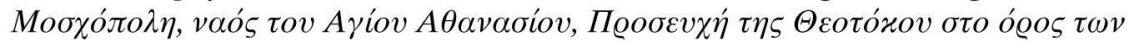

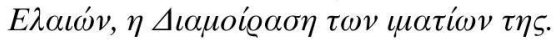

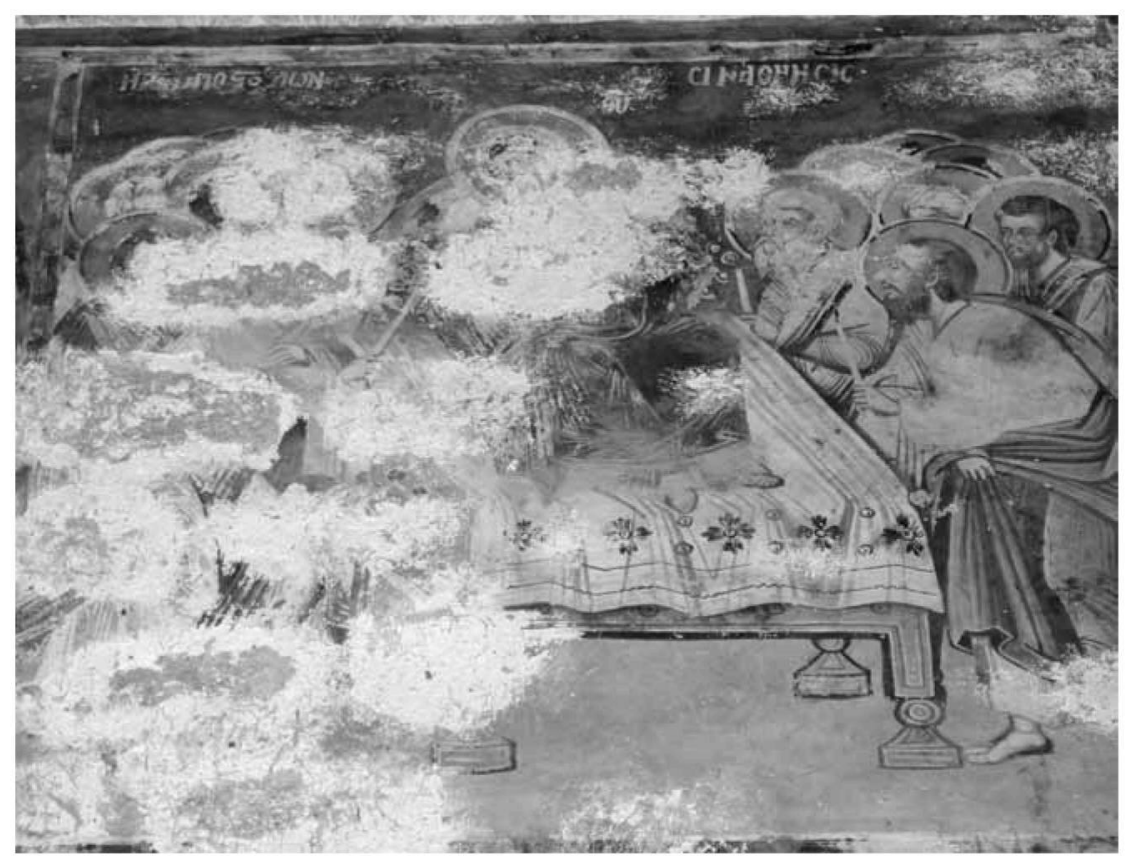

Abb. 4: Voskopoje, Athanasioskirche, Versammlung der Apostel am Bett Mariens.

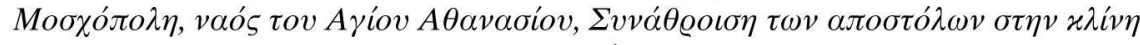

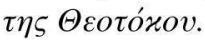




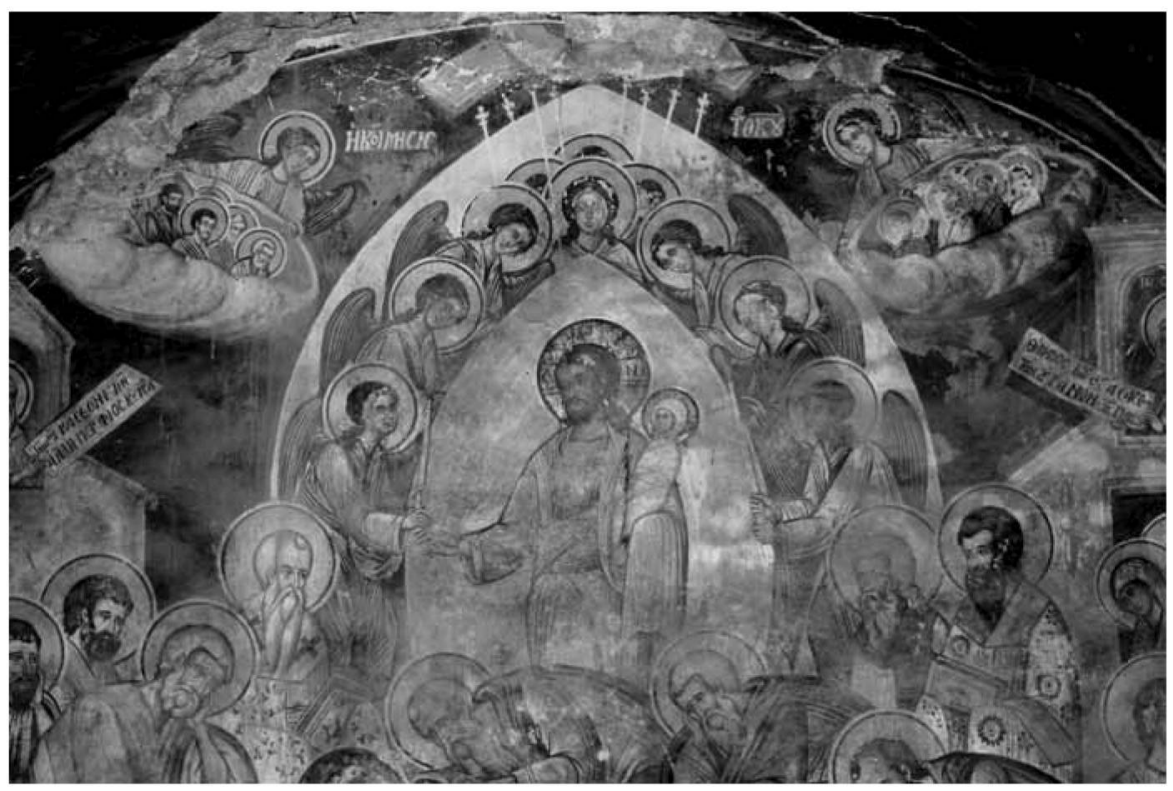

Abb. 5: Voskopoje, Athanasioskirche, Koimesis.

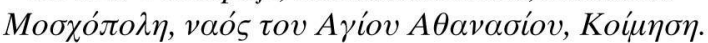

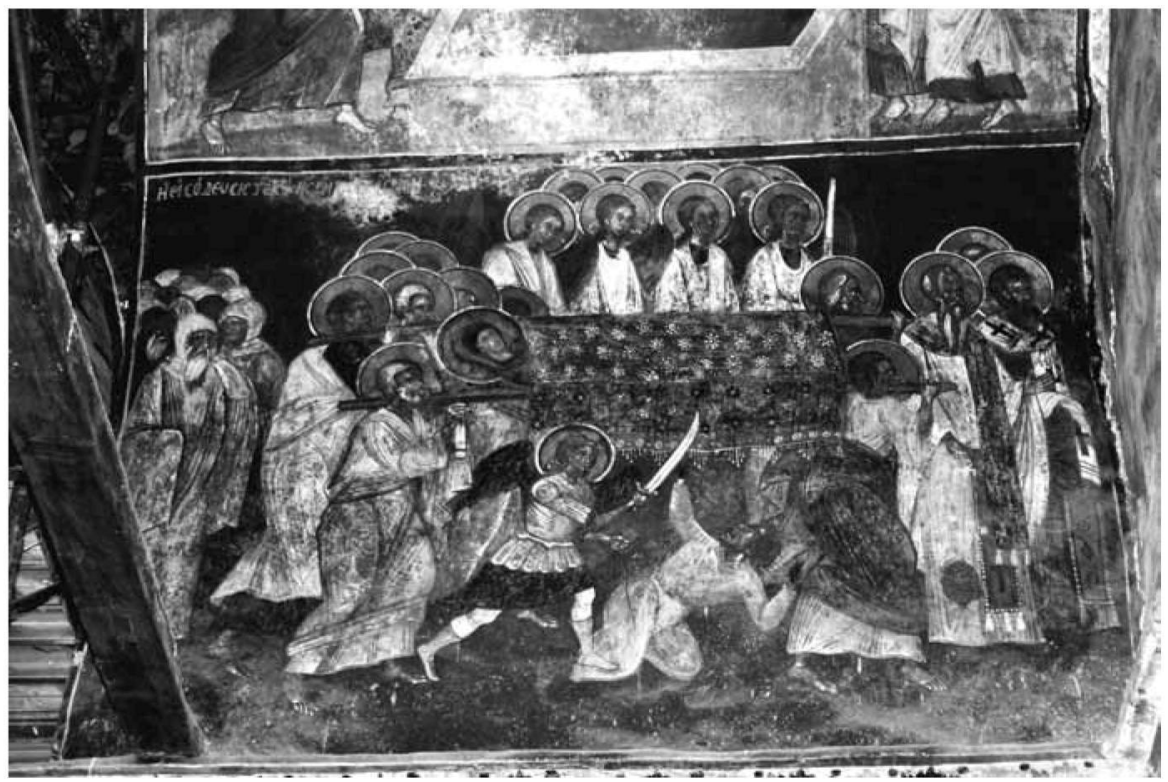

Abb. 6: Voskopoje, Athanasioskirche, Überführung des Leichnams zum Grab.

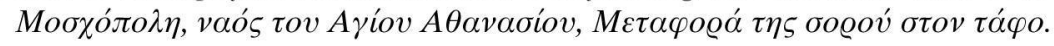




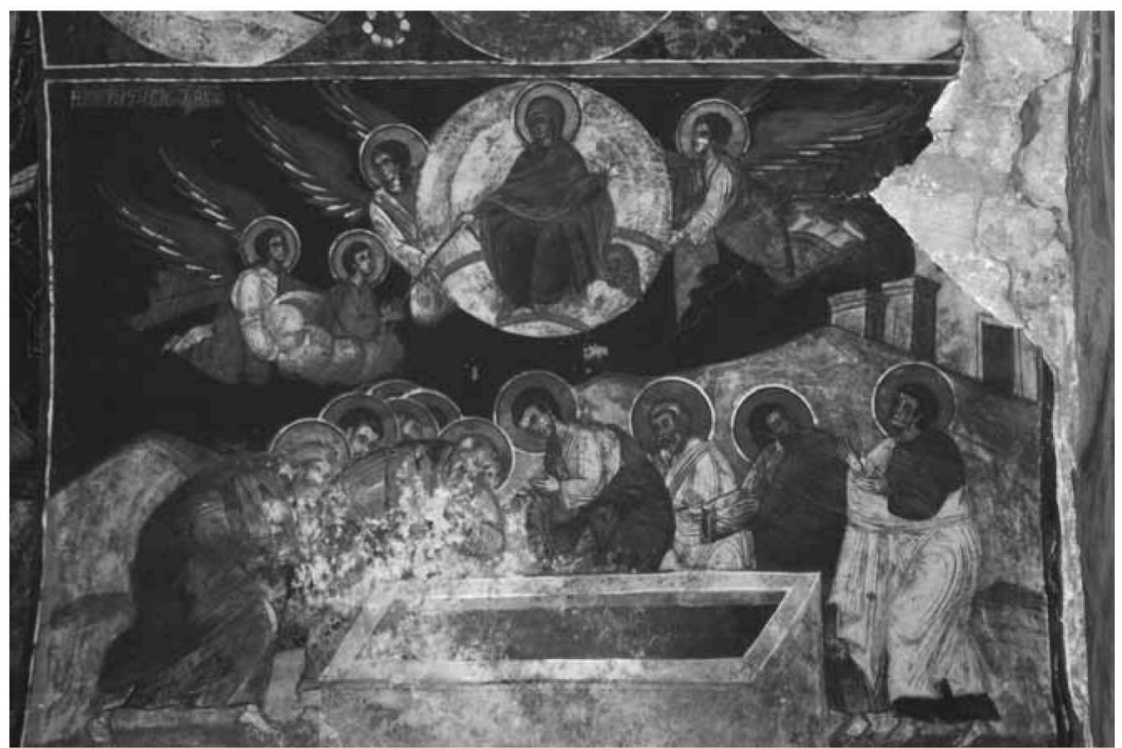

Abb. 7: Voskopoje, Athanasioskirche, Apostel am leeren Grab, Leibliche Auffahrt Mariens.

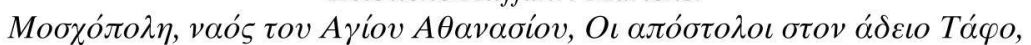

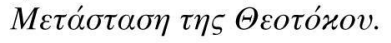

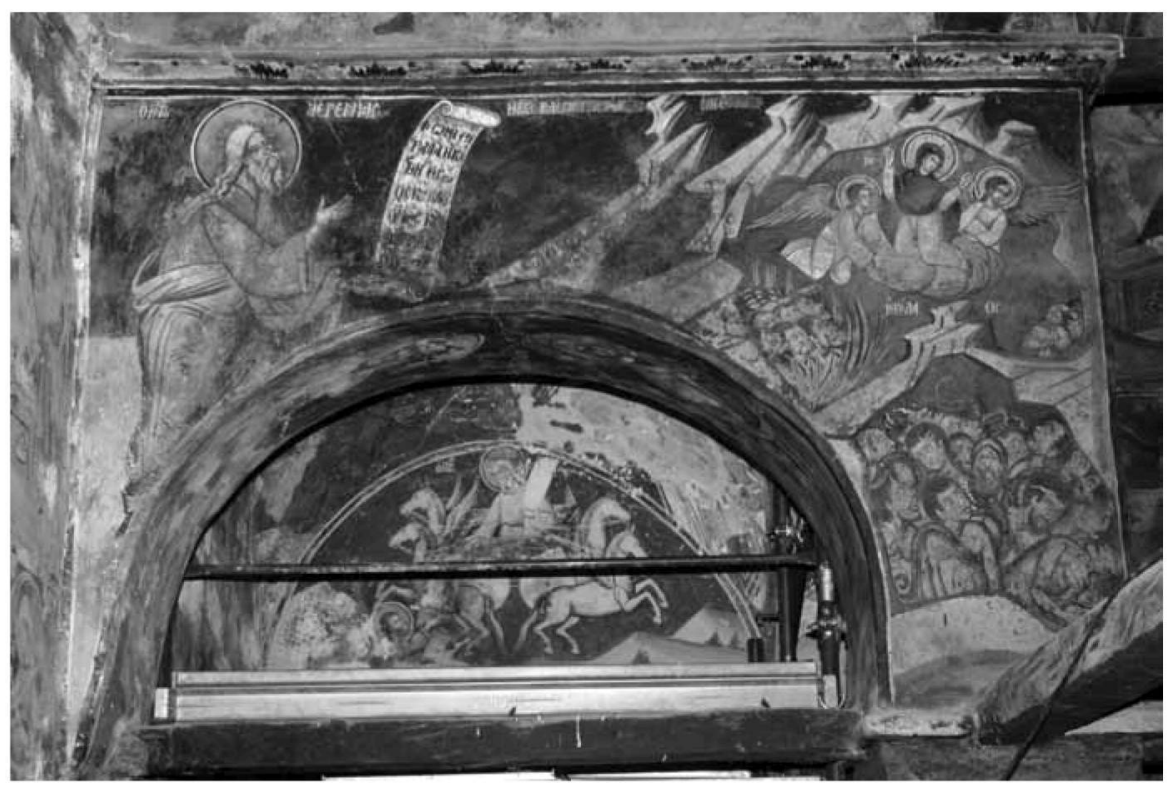

Abb. 8: Voskopoje, Athanasioskirche, Höllenfahrt Mariens.

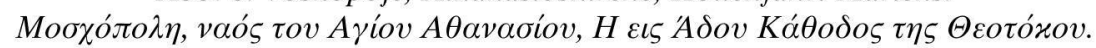




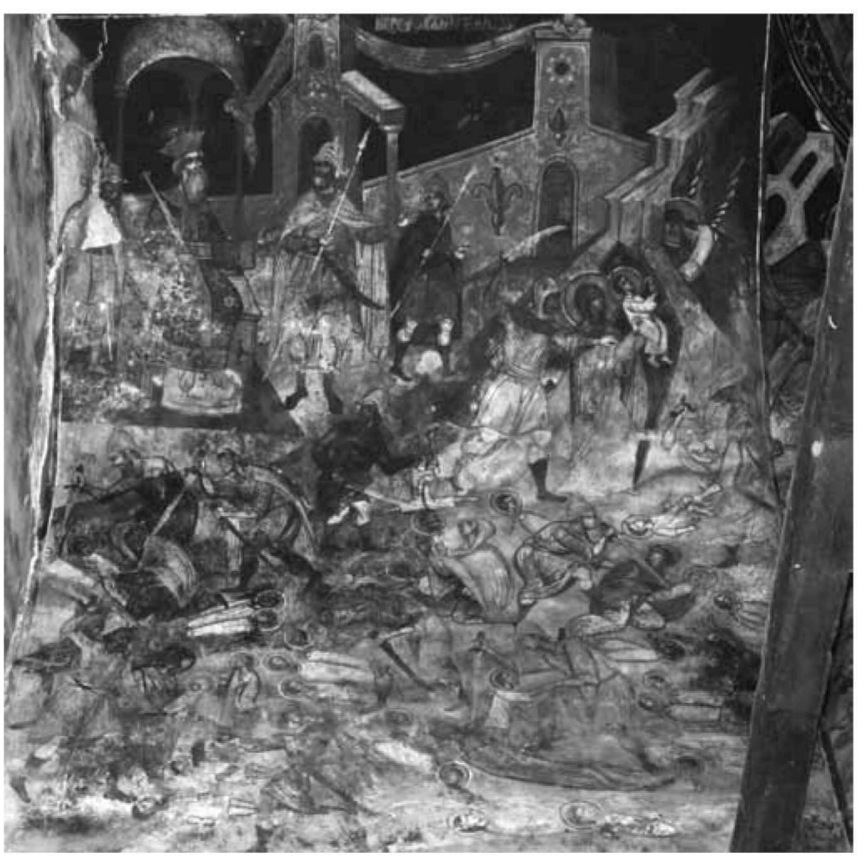

Abb. 9: Voskopoje, Athanasioskirche, Kindermord zu Bethlehem.

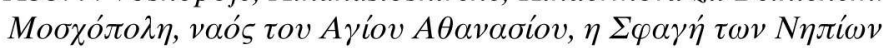
$\sigma \tau \eta B \eta \theta \lambda \varepsilon \varepsilon \dot{\mu} \mu$.

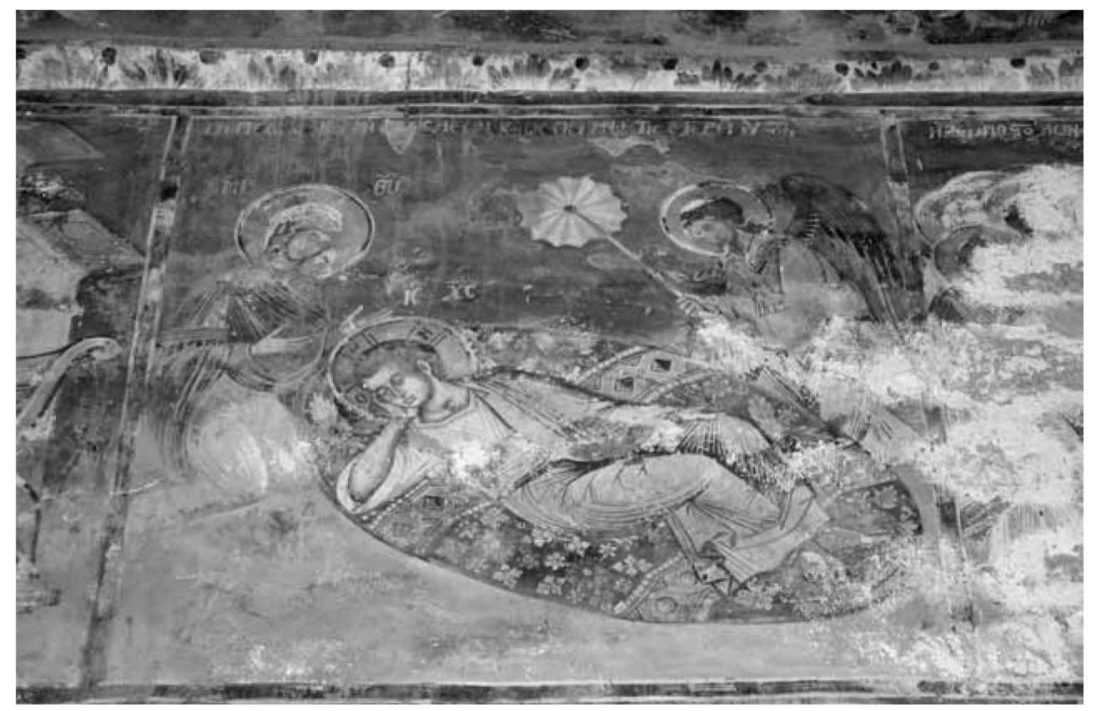

Abb. 10: Voskopoje, Athanasioskirche, Christus Anapeson.

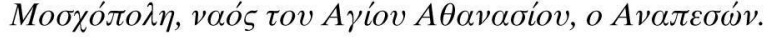




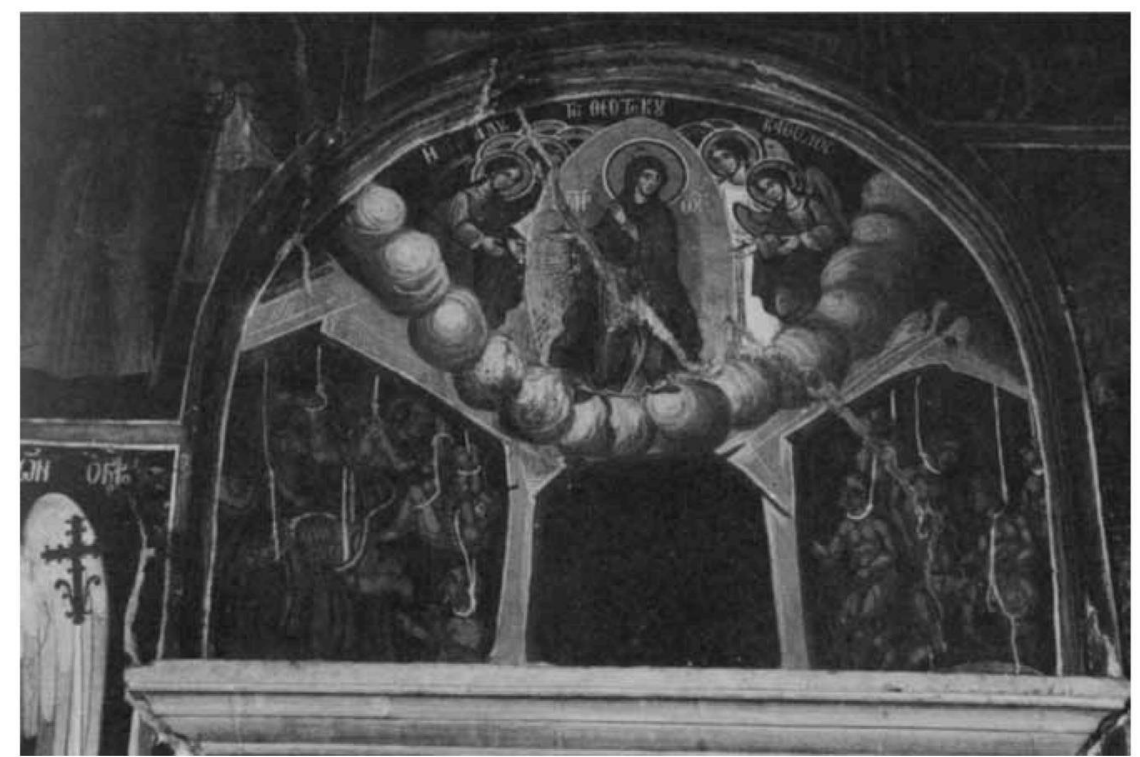

Abb. 11: Athos, Xeropotamou-Kloster, Fresko, Höllenfahrt Mariens.

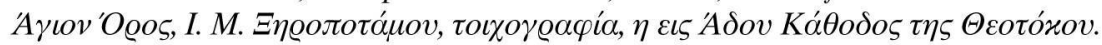

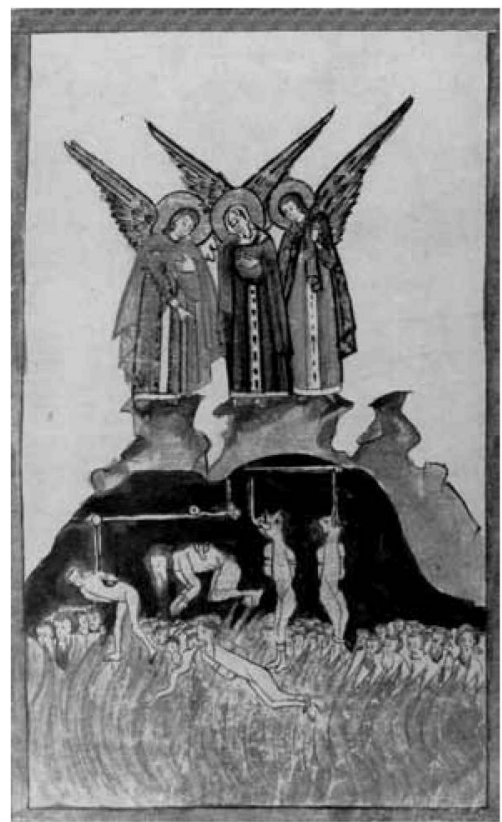

Abb. 12: Moskau, Staatliches Museum, Buchmalerei, Höllenfahrt Mariens.

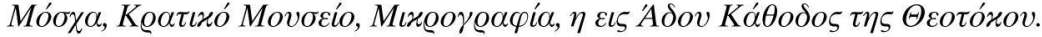

